Review Paper

\title{
Nanopolyphenols: a review of their encapsulation and anti-diabetic effects
}

\author{
Theresa F. Rambaran ${ }^{1}$ D
}

Received: 25 March 2020 / Accepted: 19 June 2020 / Published online: 6 July 2020

(C) The Author(s) $2020 \quad$ OPEN

\begin{abstract}
Polyphenols are believed to possess numerous health benefits and can be grouped as phenolic acids, flavonoids or non-flavonoids. Research involving the synthesis of nanopolyphenols has attracted interest in the areas of functional food, nutraceutical and pharmaceutical development. This is in an effort to overcome current challenges which limit the application of polyphenols such as their rapid elimination, low water-solubility, instability at low $\mathrm{pH}$, and their particle size. In the synthesis of nanopolyphenols, the type of nanocarrier used, the nanoencapsulation technique employed and the type of polymers that constitute the drug delivery system are crucial. For this review, all mentioned factors which can influence the therapeutic efficacy of nanopolyphenols were assessed. Their efficacy as anti-diabetic agents was also evaluated in 33 publications. Among these were phenolic acid (1), flavonoids (13), non-flavonoids (17) and polyphenolrich extracts (2). The most researched polyphenols were quercetin and curcumin. Nanoparticles were the main nanocarrier and the size of the nanopolyphenols ranged from 15 to $333 \mathrm{~nm}$ with encapsulation efficiency and drug loading capacities of $56-97.7 \%$ and $4.2-53.2 \%$, respectively. The quantity of nanomaterial administered orally ranged from 1 to $300 \mathrm{mg} / \mathrm{kg} /$ day with study durations of 1-70 days. Most studies compared the effect of the nanopolyphenol to its freeform and, in all but three cases, significantly greater effects of the former were reported. Assessment of the polyphenol to understand its properties and the subsequent synthesis of its nanoencapsulated form using suitable nanocarriers, polymers and encapsulation techniques can result in effective therapeutic agents for the treatment of diabetes.
\end{abstract}

Keywords Nanopolyphenols · Nanoencapsulation · Nanomedicine $\cdot$ Nanocarrier $\cdot$ Diabetes

\section{Introduction}

Phenolics are compounds having one or more aromatic rings which possess at least one hydroxyl group. Polyphenols are a group of secondary metabolites with phenolic structural features and is a general term used to refer to several sub-groups of phenolic compounds. These ubiquitous compounds are the largest group of phytochemicals and have been suggested to play critical roles in the growth and reproduction, color, and also the defense mechanism of plants against pathogens, parasites and predators [1, 2]. These compounds are also stated to be beneficial to health and are believed to be the most abundant group of compounds in the diet with an average adult being estimated to have a total dietary intake of $1 \mathrm{~g}$ polyphenol/day [3].

Numerous biological properties have been suggested for polyphenols and included among these are antioxidant, antimicrobial, anti-cancer, anti-inflammatory and anti-diabetic effects [4-8]. For this review we will however focus only on their anti-diabetic activity. Polyphenols are believed to be able to confer anti-diabetic effects via various mechanisms through their ability to: increase insulin secretion, insulin sensitivity and insulin-dependent

Theresa F. Rambaran, theresa.rambaran@umu.se | 1 Department of Public Health and Clinical Medicine, Section of Sustainable Health, Umeå University, 90187 Umeå, Sweden. 
glucose uptake, inhibit glucose absorption in the intestine by sodium-dependent glucose transporter 1 (SGLT1), reduce hepatic glucose output, and influence the gut microbiome [9-12]. These effects have been observed in basic research using animal models and have been confirmed in some clinical trials [13-15].

The ability of dietary polyphenols to regulate glucose homeostasis would suggest that they can be used for the prevention and management of diabetes. There are however several challenges in achieving this outcome. While positive effects of polyphenols (as it relates to their antidiabetic effect in both healthy and diseased subjects), have been suggested in numerous basic research and clinical trials, this outcome is inconsistent. These inconsistencies are due to several factors including: the quantity of polyphenols used in vitro and in vivo to demonstrate effects are usually significantly higher than the amount generally contained in the human diet; and more importantly, the ability of the compounds to exert their effect in target tissues is significantly reduced due to their low bioavailability in humans $[16,17]$. While there are several extrinsic factors which can impact the bioavailability of polyphenols such as food matrix, gut microbiota and rapid elimination, some of the main challenges include intrinsic factors such as their low water-solubility, instability at low
$\mathrm{pH}$, and the particle size of the compounds [18-20]. The synthesis of nanomaterials to improve the bioavailability of polyphenols is therefore a trending area of study. Methods which have been utilized in the preparation of these nanosystems are able to impact the physical and chemical properties of polyphenols. The focus of this study is therefore to review the encapsulation of nanopolyphenols and evaluate their efficacy as anti-diabetic agents. The number of studies in humans are limited and so the evaluation of the anti-diabetic potential of nanopolyphenols was done using in vivo diabetic models. The general framework of this review is schematically represented in Fig. 1.

\section{Classification of polyphenols}

Polyphenolic compounds are diverse in chemical structure and this is one basis on which classification can be achieved. The most common variations in the chemical skeleton include the degree of oxidation, hydroxylation, methylation and glycosylation. The main classes of polyphenols include phenolic acids, flavonoids and nonflavonoids with subclasses of the latter including stilbenoids, lignans, tannins, and diarylheptanoids (Fig. 2). Less common subclasses of non-flavonoid polyphenols include
Fig. 1 Schematic representation of the topics covered in the review

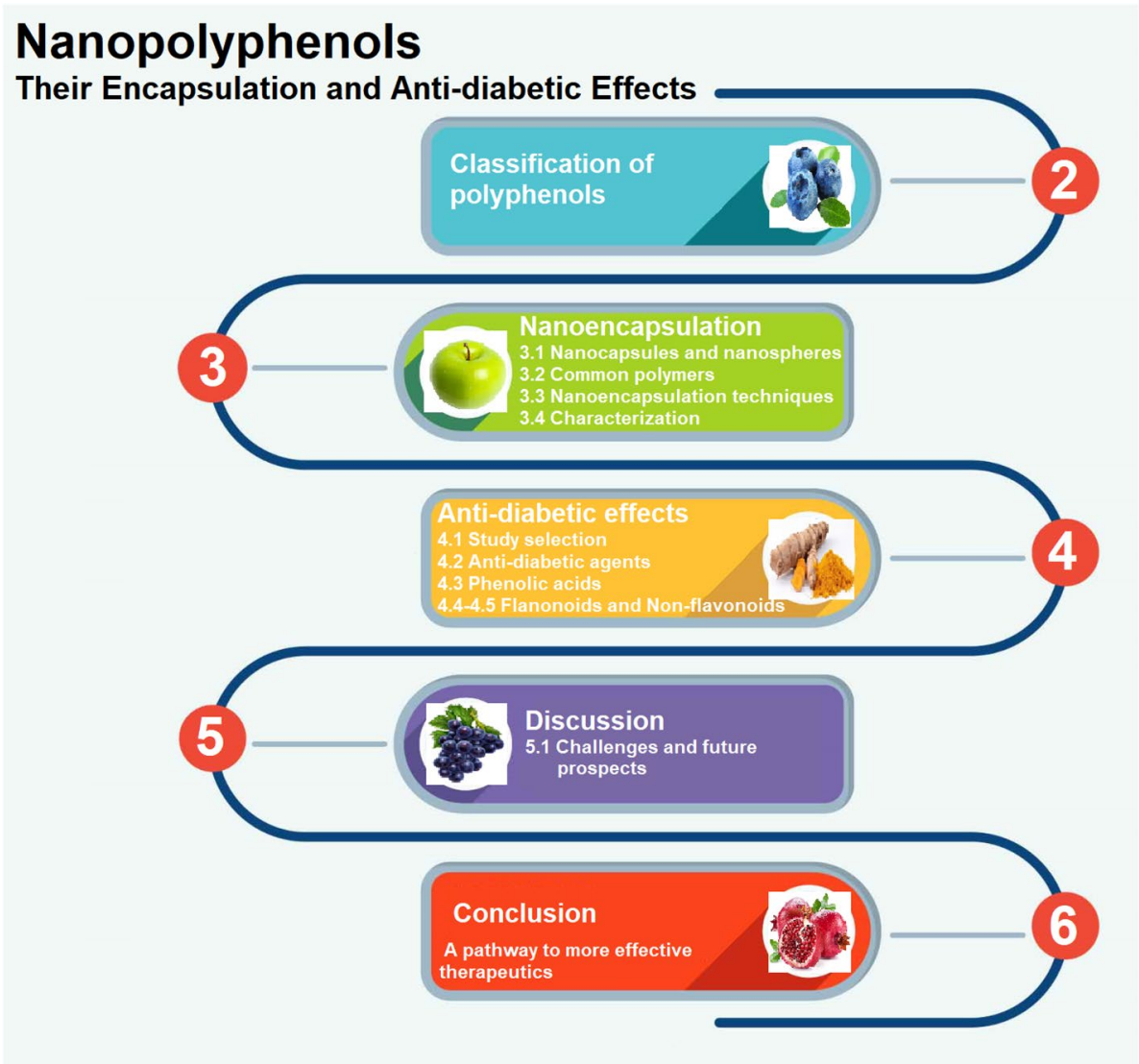




\section{Polyphenols}

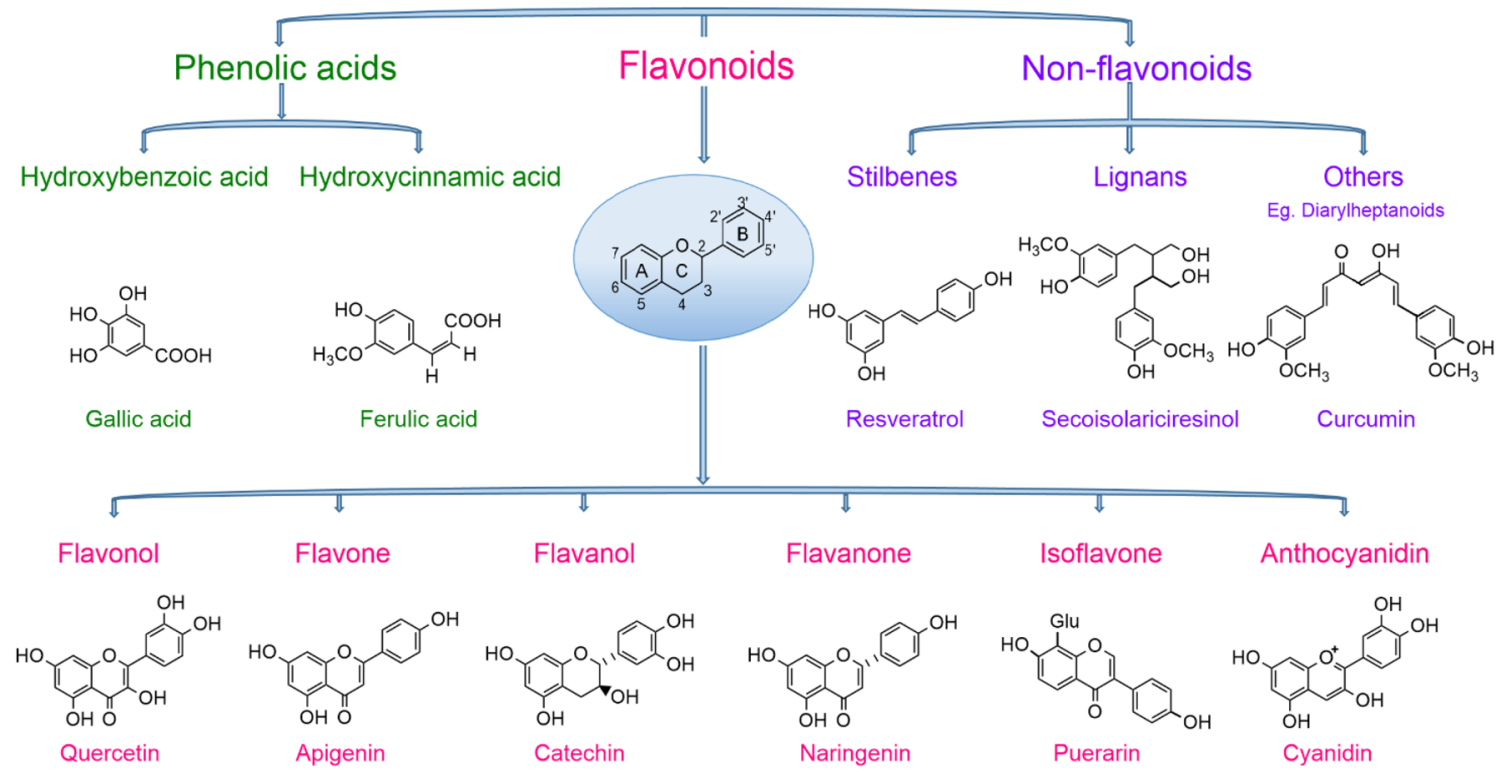

Fig. 2 Classification of polyphenols

polyphenolic amides and anthraquinones. There are several accounts of the anti-diabetic effects of each class of polyphenol outlined [21-26].

About one-third of dietary polyphenols are phenolic acids and these-which can be categorized as hydroxybenzoic or hydroxycinnamic acids-are present in both their bound and free-forms in plants [27]. Among the benzoic acid derivatives are compounds such as ellagic acid, p-hydroxybenzoic acid, protocatechuic acid, vanillic acid and gallic acid while among the cinnamic acid derivatives are $p$-coumaric acid, caffeic acid, ferulic acid and sinapic acid $[27,28]$.

Of all the phenolics in our diet, approximately twothirds are estimated to be flavonoids [1]. These compounds have a general structure that consists of two aromatic rings ( $A$ and $B$ rings) that are linked by 3 carbons that are usually in an oxygenated heterocycle ring, or $C$ ring. Variations in the heterocyclic ring can result in several flavonoids and these can be categorized as flavonols, flavones, flavanols, flavanones, anthocyanidins and isoflavonoids. According to Puupponen-Pimiä et al. [29], flavonols and flavones are the most common phenolics in plant-based food.

Tannins are a subclass of non-flavonoid polyphenols and are comprised of both proanthocyanidins, which are condensed non-hydrolysable tannins, and hydrolysable tannins which are esters of gallic acid, gallotannins, ellagic acid and ellagitannins [6,30]. The lignan subclass of non-flavonoids are derived from phenylalanine and, along with isoflavone, is one of the major classes of phytoestrogens [31]. Common examples of lignans are enterolignans, enterodiol, enterolactone and secoisolariciresinol. Stilbenoids are hydroxylated derivatives of stilbenes and are classified as phytoalexins [32]. The most popular stilbenoid is resveratrol. Another non-flavonoid subclass is diarylheptanoids which consists of two aryl groups joined by a seven carbon chain. They can be classified into linear and cyclic diarylheptanoids; for example, curcumin and myricanone, respectively.

\section{Nanoencapsulation}

\subsection{Nanocapsules and nanospheres}

Nanomaterials are commonly defined to be of a diameter in the range of 1-100 $\mathrm{nm}$; however, in principle, these materials have a length of $1-1000 \mathrm{~nm}$ in at least one dimension [33]. Nanoencapsulation is defined as the technology of packaging nanomaterials of an active ingredient in the form of a solid, liquid, or gas, also known as the core or active, within a secondary material, named the matrix or shell, to form nanocapsules [34]. A similar technology can lead to the formation of nanospheres where the bioactive compound is uniformly dispersed in a matrix system [35]. The core (depending on design) is generally released by diffusion or as a response to triggers such as shear, $\mathrm{pH}$, or enzyme action, consequently enabling their controlled and timed delivery to a targeted site $[36,37]$. The nanocapsules or nanospheres can be used as a carrier 
for hydrophilic or lipophilic bioactive compounds and are shown in Fig. 3.

It is important to note that while nanoencapsulation is often used to describe the trapping of bioactive materials in nanoscale carriers, substances that are not therapeutically active can also be encapsulated to determine the impact of this process on dynamic behavior, electrical properties, phase transitions and so on $[38,39]$.

\subsection{Common polymers constituting nanomaterials}

Like the core of the nanomaterial, the external polymeric membrane is also of paramount importance in their synthesis. Physicochemical properties of the selected polymer play a crucial role on the responsiveness of the nanomaterial and so a number of factors have to be taken into consideration before deciding on a polymer. These include whether the polymer and its degraded products are safe and also whether the polymer possesses the necessary properties to enable achievement of the drug delivery goals; e.g. a suitable controlled release profile [40]. A critical requirement, as it relates to the safety of the material, is the need for the polymer and its degraded products to be non-toxic, non-immunogenic, and also to be biodegradable or at least be totally eliminated from the body in a short period of time so repeat administration is possible without any risk of uncontrolled accumulation [41].

The most commonly used natural biopolymers in the preparation of nanoencapsulated materials are chitosan, gelatin, sodium alginate and albumin [41-43]. These natural polymers offer a number of advantages which include being biodegradable (thus after the drug is depleted the carrier is broken down to components that are readily re-absorbed or eliminated); being biocompatible (and as a result are non-toxic in humans); allowing for adhesion to target tissues (which helps to enhance residence time and consequently the amount of absorbable drug);

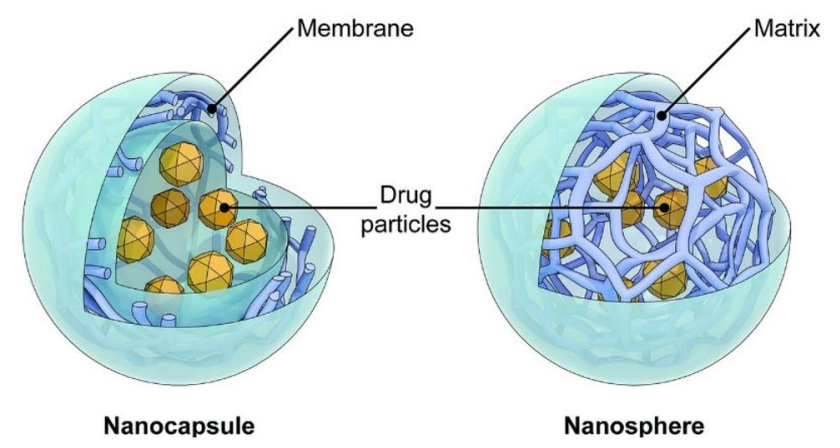

Fig. 3 A representation of the structure of a nanocapsule and a nanosphere. The image is in the public domain and is credited to the National Institutes of Health/Department of Health and Human Services [131] possessing specific receptor recognition; allowing for nonspecific protein adsorption as they provide neutral coating with low surface energy; and possessing a high amount of hydroxyl groups on their backbone (therefore allowing the incorporation of different specific ligands) [44]. Some disadvantages associated with natural polymers include a great level of variability among those derived from animal sources, complex structures, and complicated and costly extraction processes [45].

There are many synthetic polymers such as polylactides (PLA), polyglycolides (PGA), poly(lactide co-glycolides) (PLGA), and poly(vinyl alcohol) (PVA), to name a few. There are also copolymers such as poly(lactide)-poly(ethylene glycol) (PLA-PEG), and poly(lactide-co-glycolide)poly(ethylene glycol) PLGA-PEG. The use of polymeric colloidal stabilizers to prevent aggregation is also common in nanoencapsulation processes and some common ones include dextran, polysorbate 20 and polysorbate 80 [41]. Some advantages associated with the use of these synthetic materials include that they offer both greater mechanical and chemical stability, increased reproducibility due to minimized variation between batches, reduced nonspecific protein binding, ease of modification, and tunable properties [46, 47]. Disadvantages, on the other hand, include the possibility of the synthetic polymer being toxic and non-degradable and this is coupled with a complex and costly production process [45].

Along with the use of natural and synthetic materials in the design of nanocarriers, there are a few studies which have focused on the use of the bioactive compounds as the nanocarrier to develop 'self-carrying nanodrug delivery systems' [48]. This approach aims to develop functional carriers and is expected to have better biocompatibility than drug delivery systems derived from synthetic materials and also exhibit intrinsic therapeutic efficacy. The functional molecules can be either chemically attached to the core or shell or physically bound [49]. The advantages derived from this synthesis protocol include increased stability and water solubility, the nanocarrier is not susceptible to compound leakage, and it is also non-toxic with a high carrier-to-drug ratio [50, 51]. The formulation of these self-carrying natural nanocarriers however pose challenges in their synthesis, characterization, purification, mass production, and quality control (uniformity and reproducibility). They are also more costly to produce and these factors, overall, limit their prospects as biomedical therapies [48].

\subsection{Nanoencapsulation techniques}

Nanomaterials can be made using a range of nanocarriers which serve as a transport module for bioactive materials. Pharmaceutical nanocarriers include nanospheres, 
nanocapsules, nanoparticles, nanoemulsion, nanoliposomes and nanoniosomes (non-ionic surfactant vesicles). These nanoscale drug delivery systems can be natural or synthetic and can transport either lipophilic or hydrophilic molecules. They can be classified based on their origin (e.g. lipid-based and biopolymer nanocarriers), their method of preparation (e.g. electrospun and electrosprayed nanocarriers) and also based on their composition as outlined in Fig. 4 [52, 53]. The use of inorganic nanomaterials such as silica, gold and carbon-based nanostructures are being used extensively for drug delivery in cancer therapy [54]. Some nanocarriers such as solid lipid nanoparticles (SLNs) (a polymeric nanocarrier) have been further modified over time to improve their stability and loading capacity and this resulted in the formation of nanostructured lipid carriers (NLCs) [55]. The loading capacity of a nanocarrier is the amount of drug loaded per unit weight. This is an important parameter which determines the quantity of drug that can be transported and released after administration. As the size of the nanocarrier decreases, loading capacity also decreases; henceforth, both properties have to be considered in determining the quantity of nanocarrier needed for therapeutic efficacy.

Nanocarriers can be made using several nanoencapsulation techniques which can be divided into physical, physicochemical and chemical methods as outlined in Fig. 5. These techniques result in variations in the resulting drug delivery systems and each has its own advantages and disadvantages which have been outlined in several studies
$[41,56]$. Nanoencapsulation techniques used to synthesize nanomaterials are either top-down or bottom-up approaches. A top-down approach, as its name suggests, involves the size reduction and structure shaping of the material using specific methods (e.g. emulsification-solvent evaporation) while the bottom-up approach allows for the self-assembly and self-organization of molecules to yield nanomaterials (e.g. coacervation) [57]. Examples of the types of nanomaterials that can be synthesized using the categories of nanoencapsulation techniques outlined in Fig. 5 are as follows. A supercritical anti-solvent processing technique, which is a physical method of nanoencapsulation, can be used for the synthesis of polymeric nanoparticles. This protocol involves the supersaturation and solidification of the nanomaterial following exposure to another solvent (or multiple solvents) in which the material is sparingly soluble. Recovery of the nanomaterial can then be achieved by drying. Interfacial polycondensation has also been used for the synthesis of polymeric nanoparticles. Interfacial polycondensation which is a chemical nanoencapsulation technique is a type of irreversible polymerization at the interface between an aqueous difunctional monomer and an inert immiscible organic solvent containing a complementary difunctional monomer. Nanogels, which can result from physicochemical methods of nanoencapsulation, are a class of nanoparticles which may be synthesized via ionic interactions. This synthesis is derived from innate ionic forces and particle-particle interactions present in a colloidal system which result in a

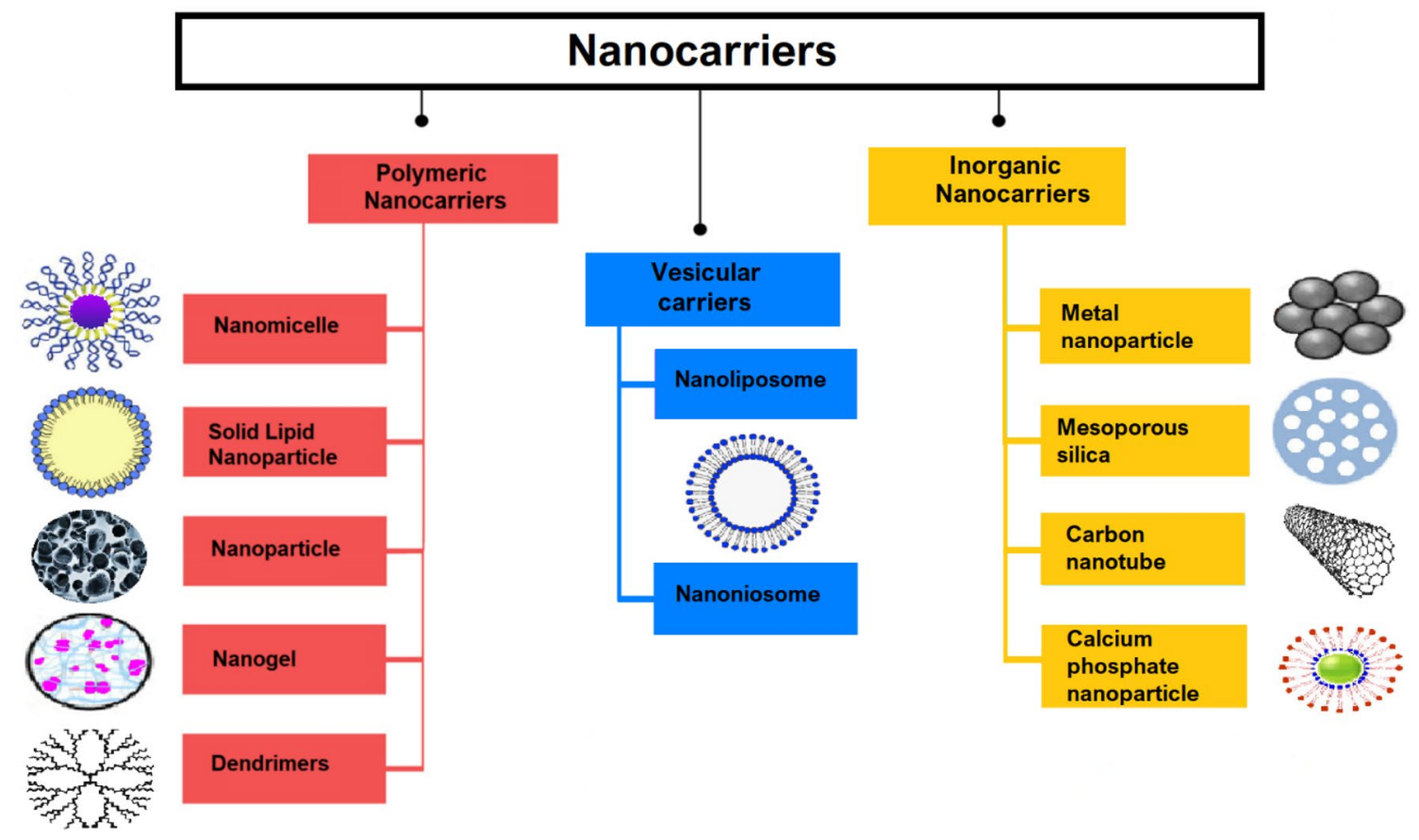

Fig. 4 Types of nanocarriers 


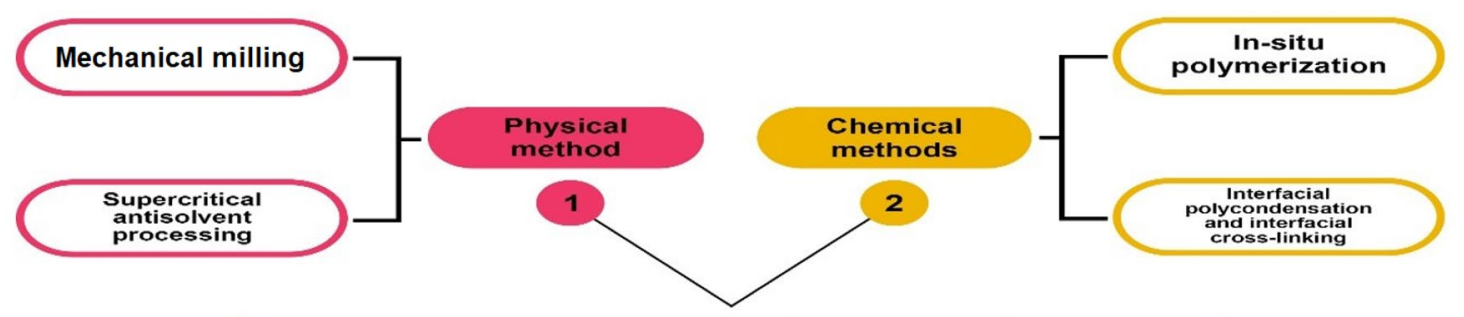

Nanoencapsulation Techniques

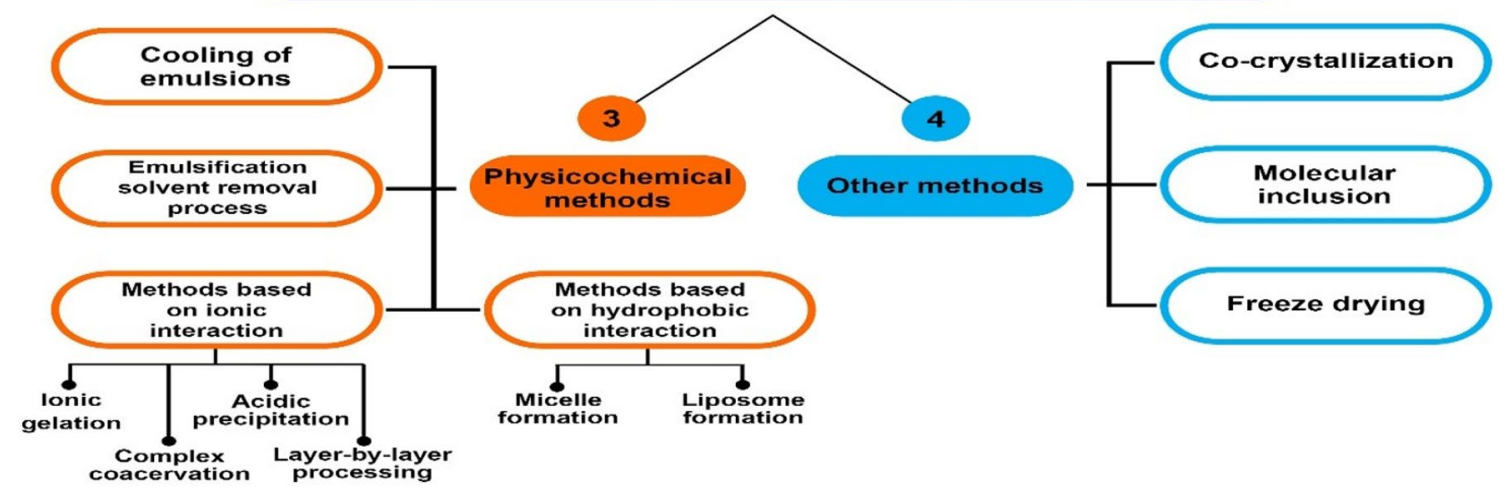

Fig. 5 Nanoencapsulation techniques

gel network formed by chemical cross-linking [58]. Freeze drying is a good technique to improve the long-term stability of colloidal nanoparticles. This technique lyophilizes the nanomaterial and the conditions that will yield powders that do not aggregate after resuspension and storage are most ideal.

The nanoencapsulation technique and delivery system used in the development of the nanoscale bioactives are able to alter various physicochemical properties of the material such as its particle size, size distribution, surface area, shape, solubility, encapsulation efficiency and releasing mechanism [57]. As a result of this, careful selection of both the type of nanocarrier and the synthesis technique is critical.

The release rate of nanopolyphenols is determined by a combination of diffusion and erosion mechanisms [57]. The materials have low permeability and are absorbed only via active transport mechanisms [59]. Given the challenges outlined previously which result in the low bioavailability of polyphenols, some of the main benefits to be derived from the nanoencapsulation of polyphenols include the ability of these techniques (if carefully selected) to allow for targeted delivery of the compounds through the modification of surface coating or conjugation so the drug is released only when it has reached the site in the body where it is needed. This not only allows for targeted delivery but also allows the rate of delivery to be controlled. These techniques also allow for the modification of surface charge which can promote cell entry, allow for timed release of the encapsulated polyphenols in the body, extend circulation time of the compound through PEGylation and protect the compounds from degradation $[56,57]$.

\subsection{Characterization of nanomaterials}

The efficacy of a nanomaterial is greatly influenced by its physical and chemical properties. Additionally, its surface characteristics can influence its functional and physicochemical properties, and ultimately, its application. The characterization of nanomaterials is therefore critical to ensure the necessary characteristics which will allow for maximum efficacy and safety are met. There are several characterization techniques which can be used to assess different parameters of a nanomaterial and those presented in Table 1 are some of the most common ones. These techniques vary with regard to relative advantages, disadvantages, cost, efficiency, and complexity and so careful consideration is necessary when selecting one $[60,61]$. 


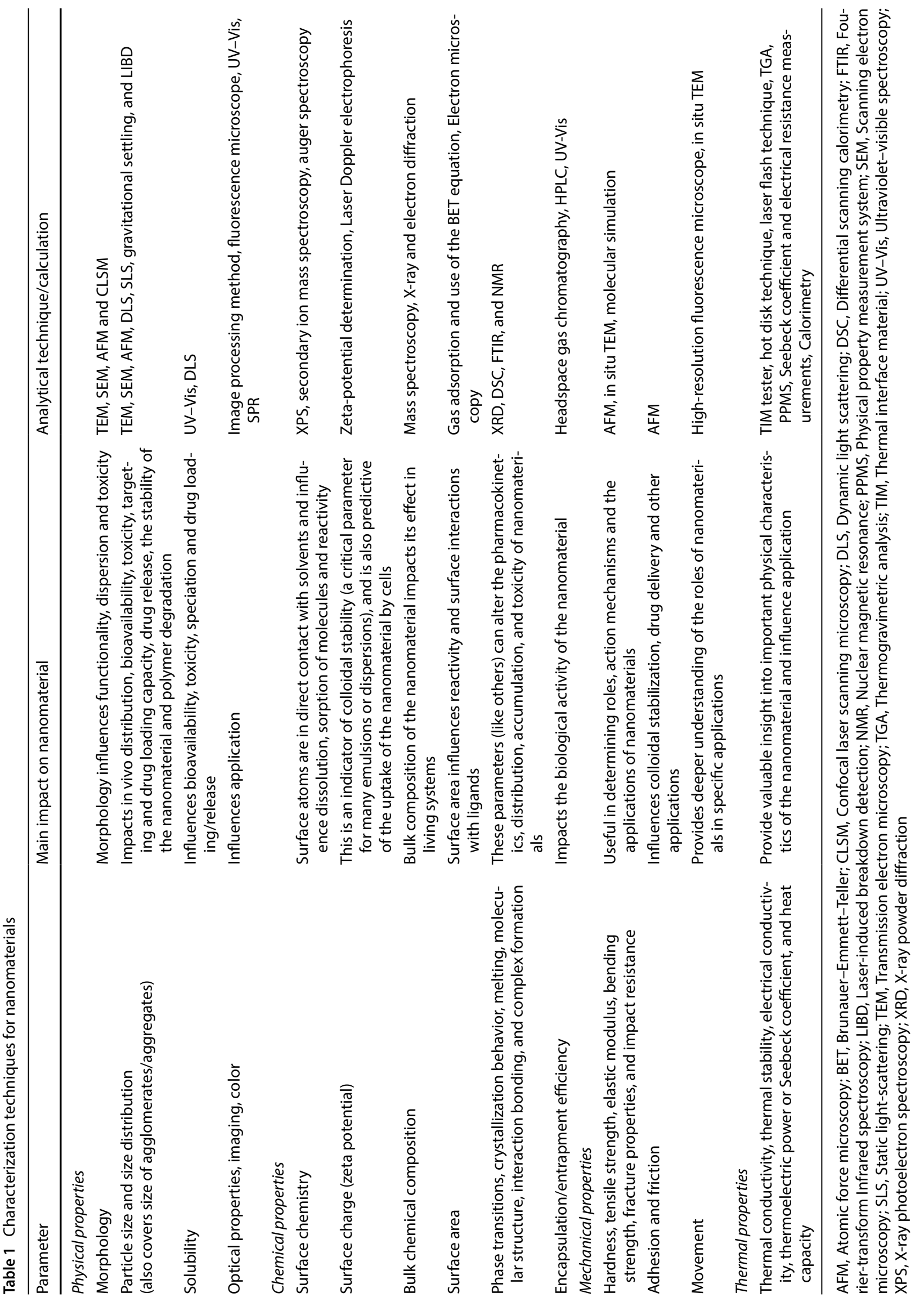




\section{Efficacy of nanopolyphenols in diabetic models}

\subsection{Study selection}

The use of nanoencapsulated polyphenols in the treatment of diabetes was studied using several databases. These include PubMed/MEDLINE, CINAHL (EBSCO), Scopus and Web of Science. The search strategy used to retrieve literature from PubMed was: ((polyphenol OR flavonoids OR flavanones OR flavanone OR flavones OR phenols OR flavonols OR kaempferol OR quercetin OR catechin OR myricetin OR rutin OR proanthocyanidin OR tannins OR resveratrol OR "isoquinoline flavonoid" OR flavanolignan OR stilbene OR "phenolic acid" OR anthocyanin OR anthocyanidin OR extract) AND (nano OR nanoparticle OR nanocapsule OR nanoconjugate OR nanocolloid OR nanomicelle OR nanoemulsion OR nanocomposite $\mathrm{OR}$ nanostructure $\mathrm{OR}$ nanoencapsulate OR nano-encapsulation) AND (glucose OR glycemia OR glycemic OR "blood sugar" OR "glycated hemoglobin" OR hba1c OR "glycosylated hemoglobin" OR insulin OR"glucose metabolism disorders" OR "metabolic disorders" OR "metabolic profile" OR hyperglycemia OR hyperglycemic OR "glucose intolerance" OR diabetes OR t2d OR t1d OR "prediabetic state" OR prediabetes)).

The search results were further refined and filtered by advanced search options, sorting by relevance and limiting search by language (English). References of the selected articles were further checked to identify relevant articles. Studies that included other biologically active components other than nanopolyphenols were included only if the nanopolyphenol was also assessed individually. Additionally, the nanoencapsulated material had to have a dimension less than $1000 \mathrm{~nm}$ to qualify as a nanopolyphenol. Data extracted from the resulting 33 studies include general study characteristics (polyphenol type and (sub)class, type of nanocarrier, size of the nanomaterial, the main components of the drug delivery system, quantity of nanopolyphenol administered, the encapsulation and/or drug loading capacity and the study duration), and the effect assessed along with the efficacy/outcome results (Table 2).

\subsection{Nanopolyphenols as anti-diabetic agents}

Several types of polyphenols and nanocarriers have been utilized in the synthesis of nanopolyphenols for the assessment of their effects in diabetic models. Of the 33 studies, outcome measures included the ability of the bioactive material to: confer anti-diabetic, hypoglycemic, anti-hyperglycemic effects or relieve oxidative stress associated with diabetes $(n=20)$, impact diabetic wound healing $(n=2)$, inhibit diabetic neuropathic pain $(n=3)$ and impact other complications associated with diabetes such as inflammation $(n=3)$, diabetic cardiomyopathy $(n=2)$, diabetic cataract or retinopathy $(n=2)$, diabetic nephropathy $(n=1)$ and diabetes-induced learning and memory impairment $(n=1)$. In all studies, streptozotocin-induced diabetic rats were used (Type 1 DM model, predominantly) with the exception of 2 studies which used alloxan-induced $[62,63]$ (Type 1 DM model) and 2 others that used sodium arsenite induced hyperglycemic rats [64] (Type $2 \mathrm{DM}$ model) and a db/db mouse model [65] (Type 2 DM model).

Nanocarriers used were mostly nanoparticles $(n=22)$, while solid lipid nanoparticles/nanostructured lipid carriers $(n=4)$, nanoemulsions $(n=3)$, nanomicelles $(n=2)$ nanospheres $(n=1)$ and nanorods $(n=1)$ were used to a lesser extent. None of the included studies outlined in Table 2 used a 'self-carrying nanodrug delivery system'. The smallest particle sizes ( 15 and $17 \mathrm{~nm}$ ) were obtained for nanorods prepared by use of a magnetic field [62] and nanospheres prepared by anti-solvent precipitation, respectively [66]. Both natural and synthetic polymers were used in the synthesis of the nanomaterials along with polymeric colloidal stabilizers. A few studies also incorporated inorganic species such as selenium and iron oxide into their matrix to assess for synergistic effects [67-69].

The quantity of nanomaterial administered orally ranged from 1 to $300 \mathrm{mg} / \mathrm{kg} /$ day. Nanopolyphenols were also administered via intravenous and topical delivery. The encapsulation efficiency and drug loading capacity of the prepared nanomaterials were within the range of $56-97.7 \%$ and $4.2-53.2 \%$, respectively. A decrease in particle size resulted in a similar decrease in drug loading capacity in all but one study for which this data was available [70]. Study durations ranged from 1 to 70 days for drugs administered orally. The effect of the nanopolyphenols was determined in relation to the free-form of the drug for $73 \%$ of the included studies $(n=24)$. Efficacy was also determined through comparisons with the drug-free nanocarrier $(n=2)$, different administered quantities of the nanopolyphenol $(n=2)$, other nanoencapsulated bioactive materials $(n=2)$, the effect of the nanodrug in treated versus untreated diabetic rats $(n=2)$ and established pharmaceuticals $(n=1)$. A few studies used an experimental design which allowed for comparisons on several of the noted premises; however, that relating to the effect of the free-form of the drug versus its nanoencapsulated counterpart was prioritized. 


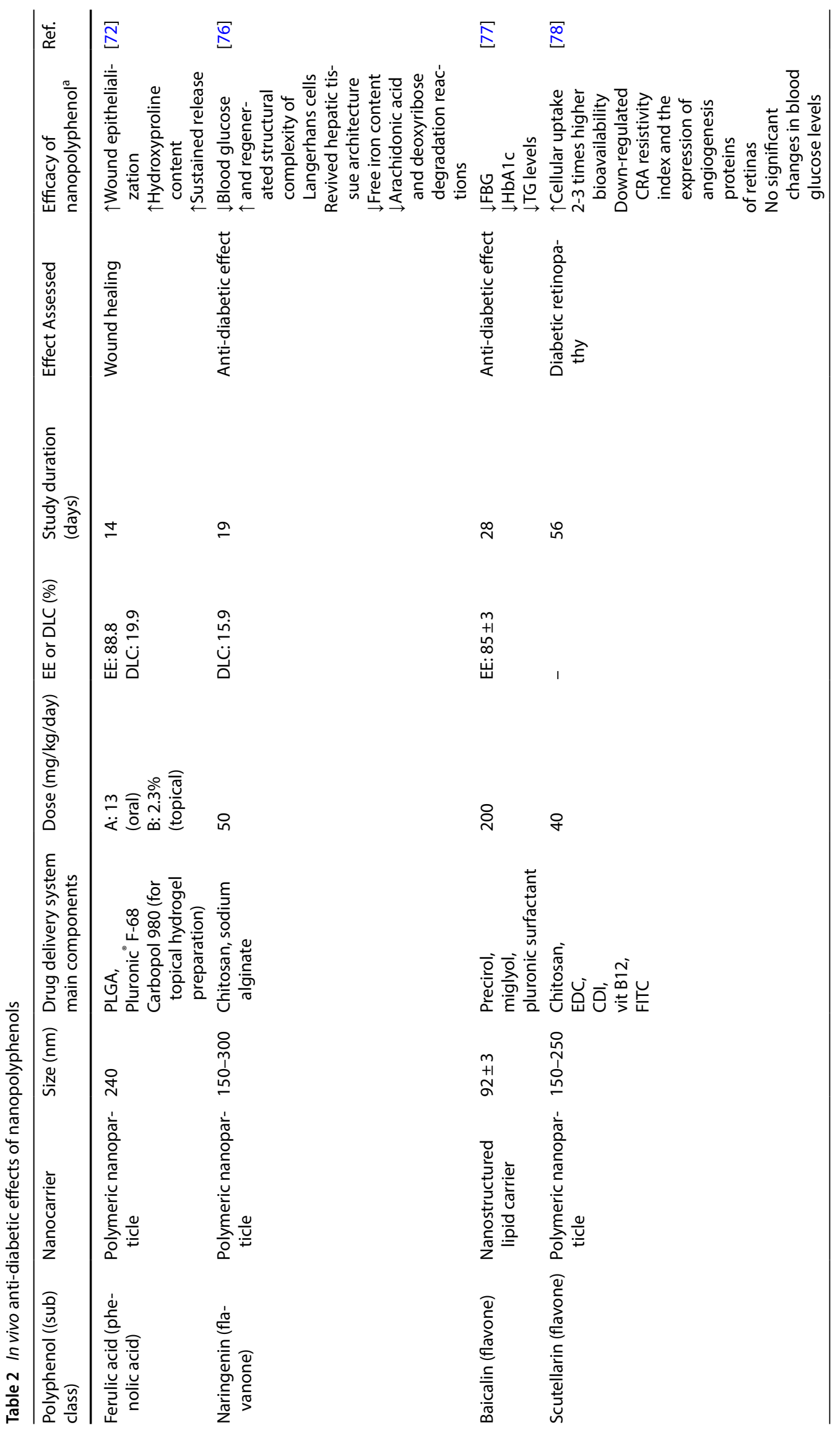




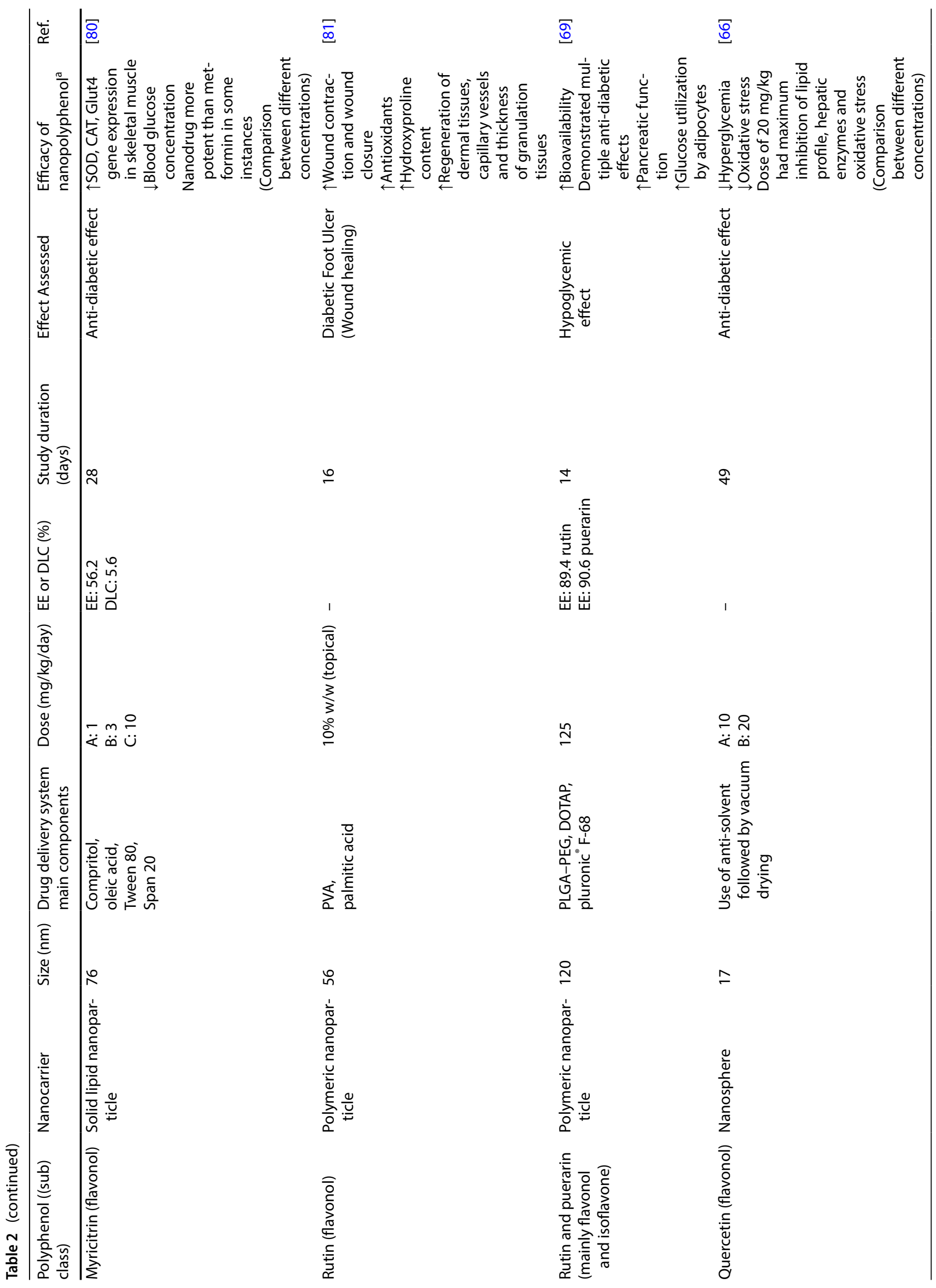

SN Applied Sciences 


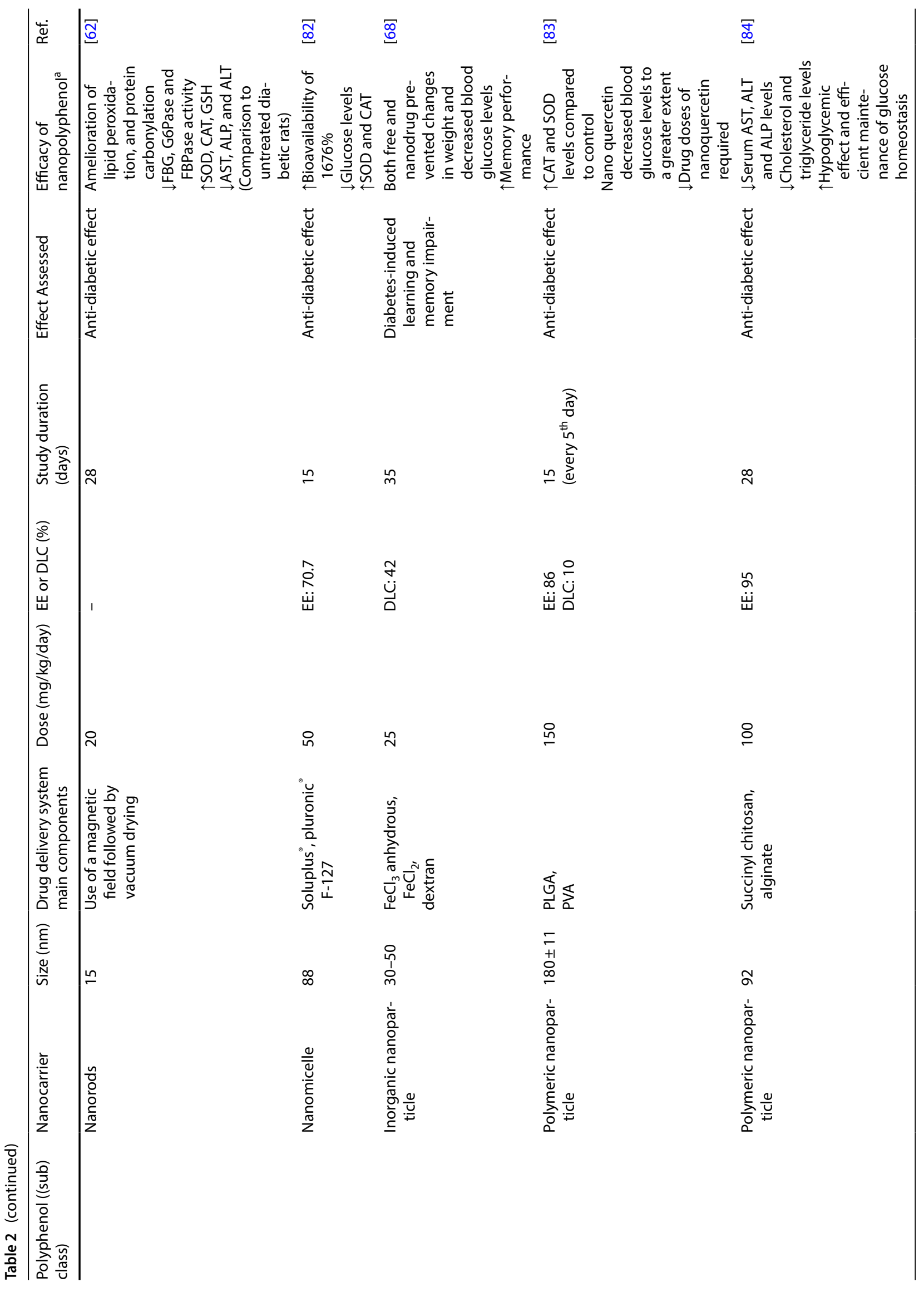




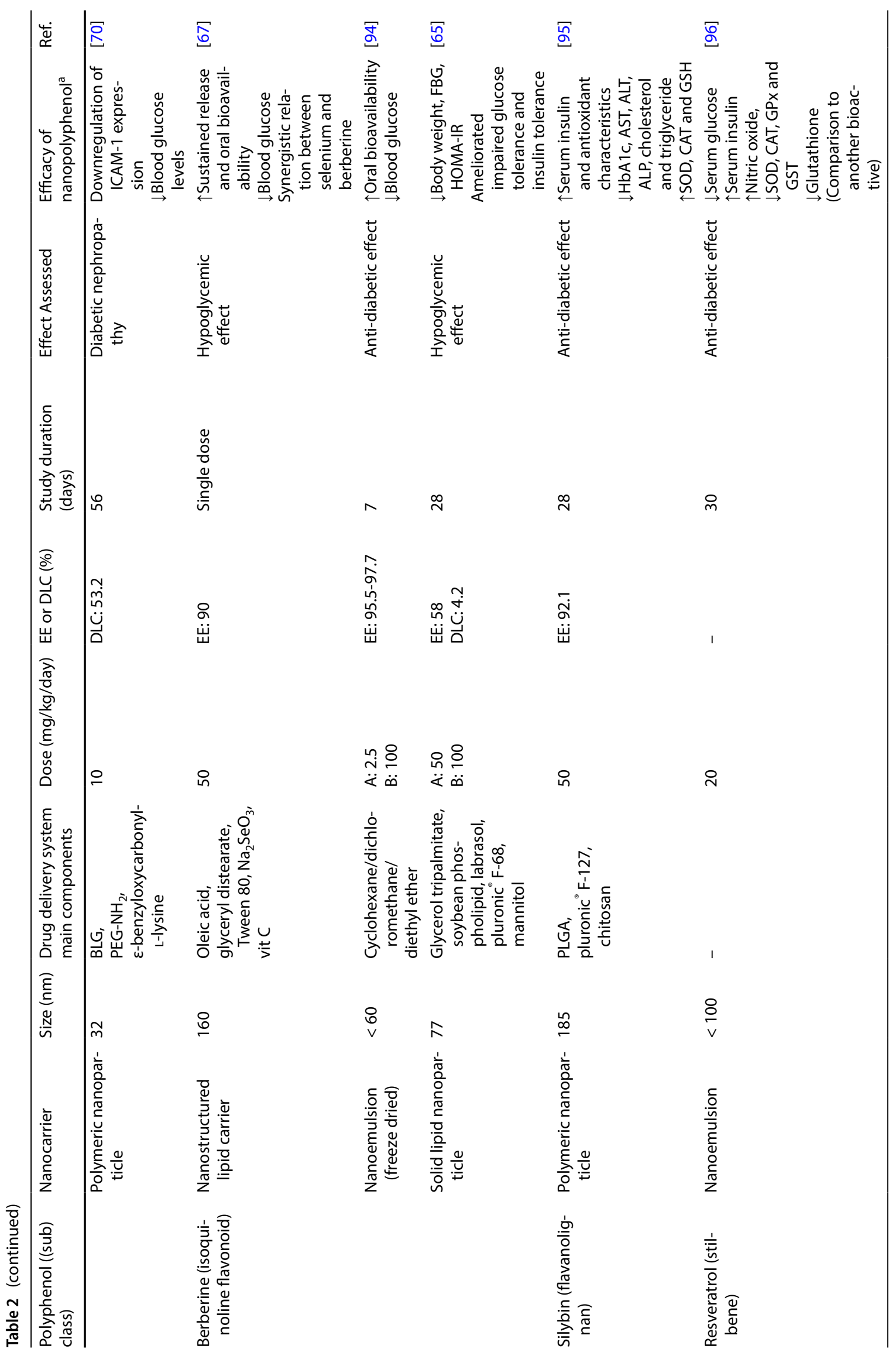




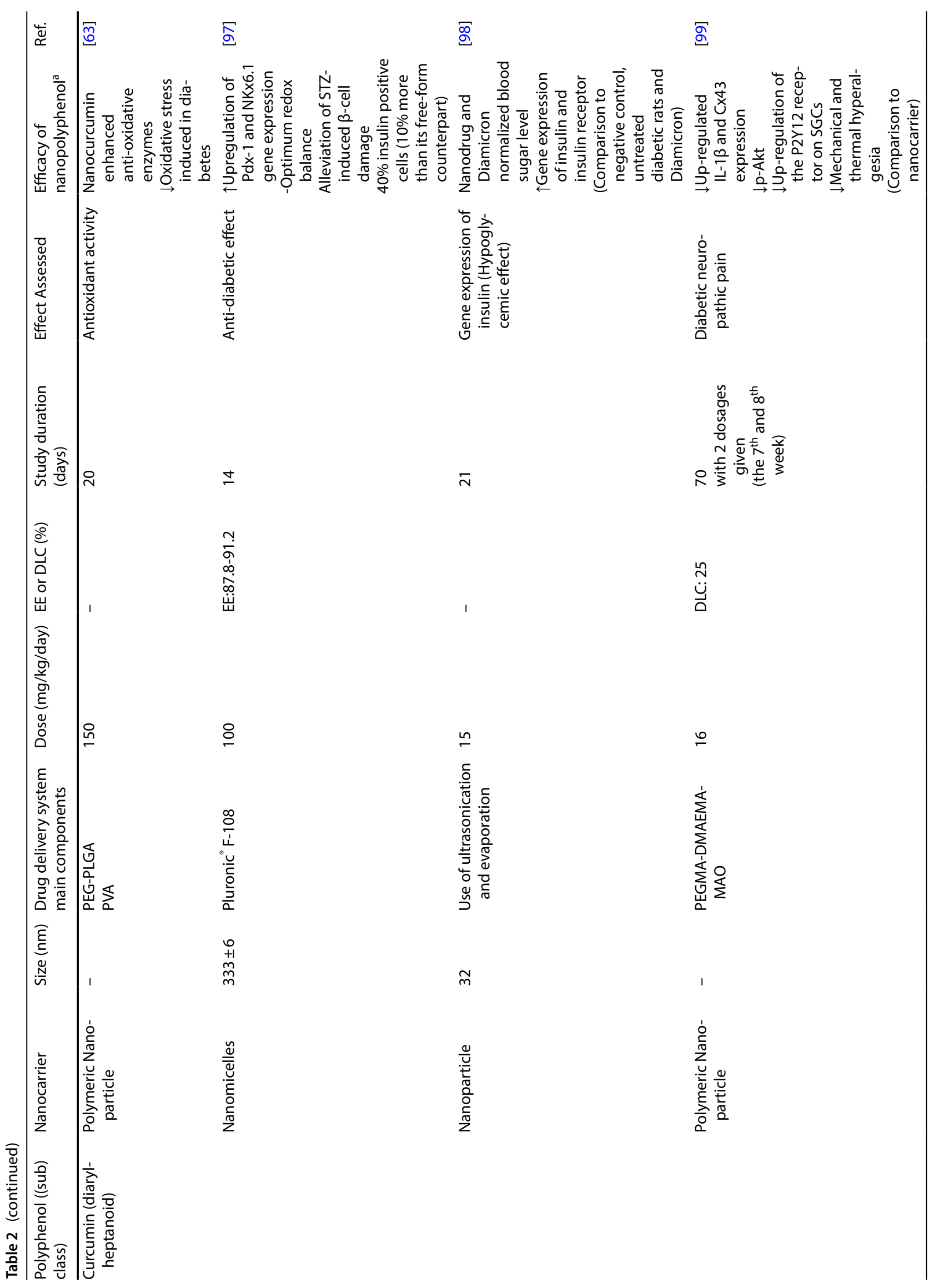




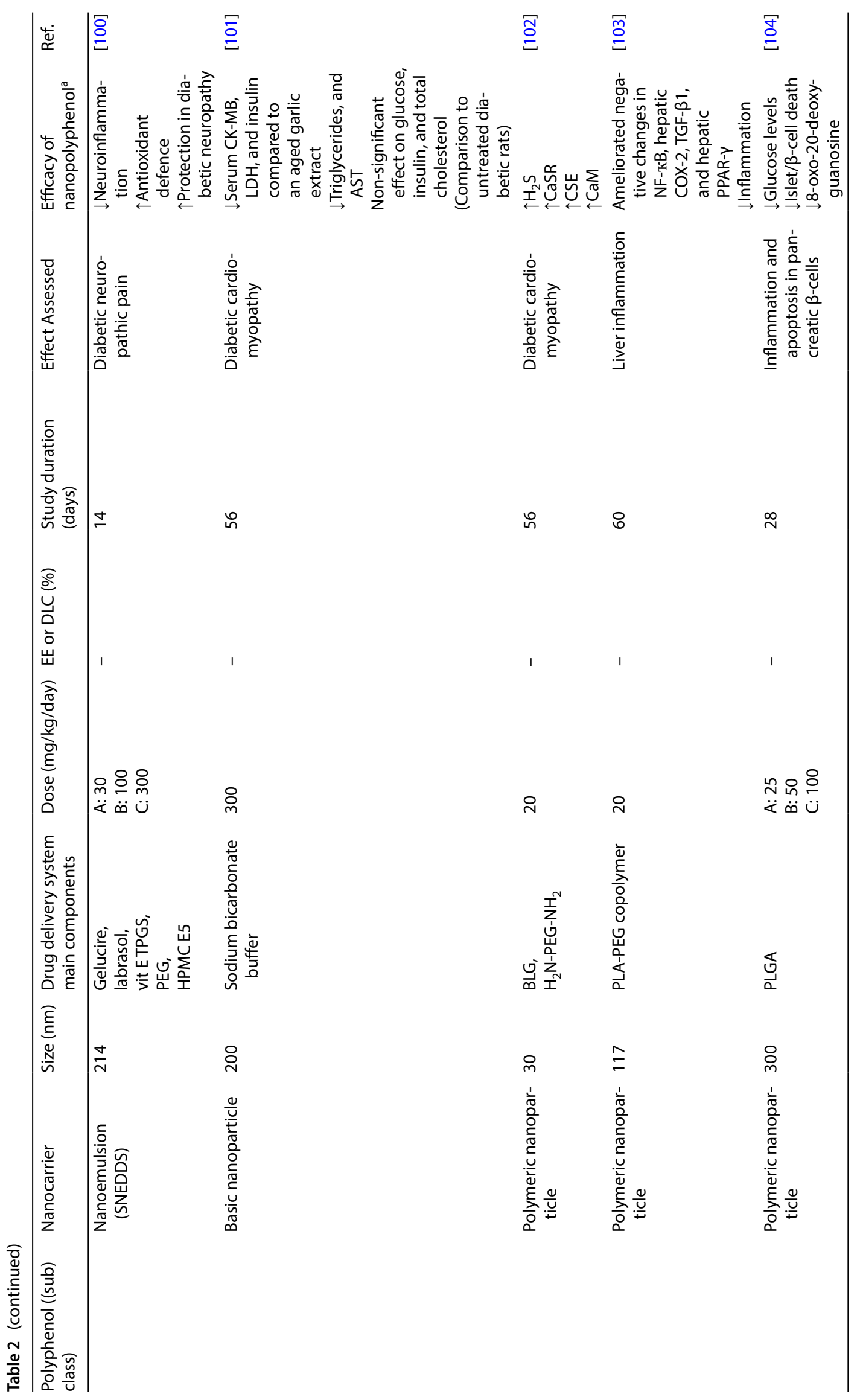




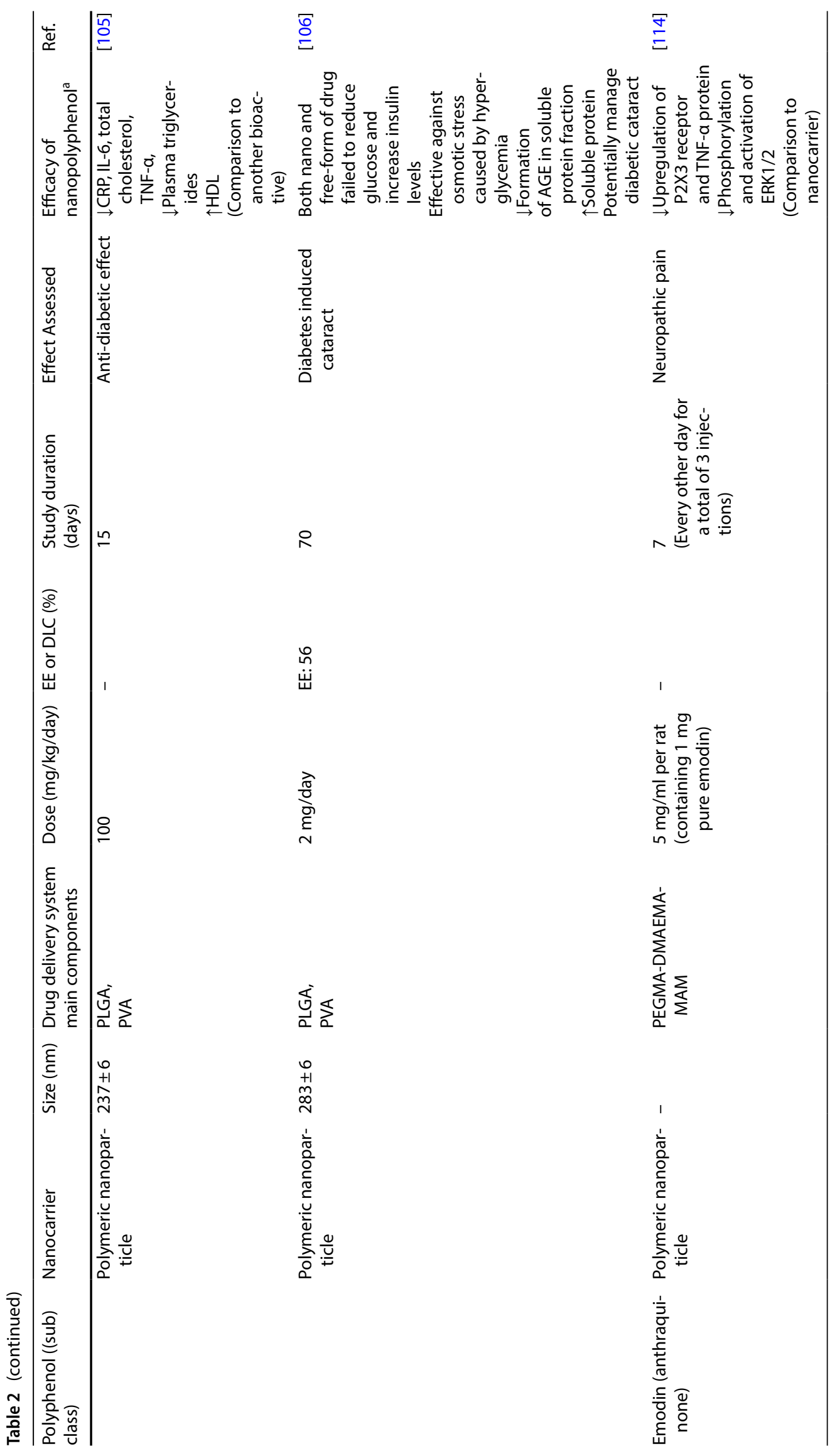




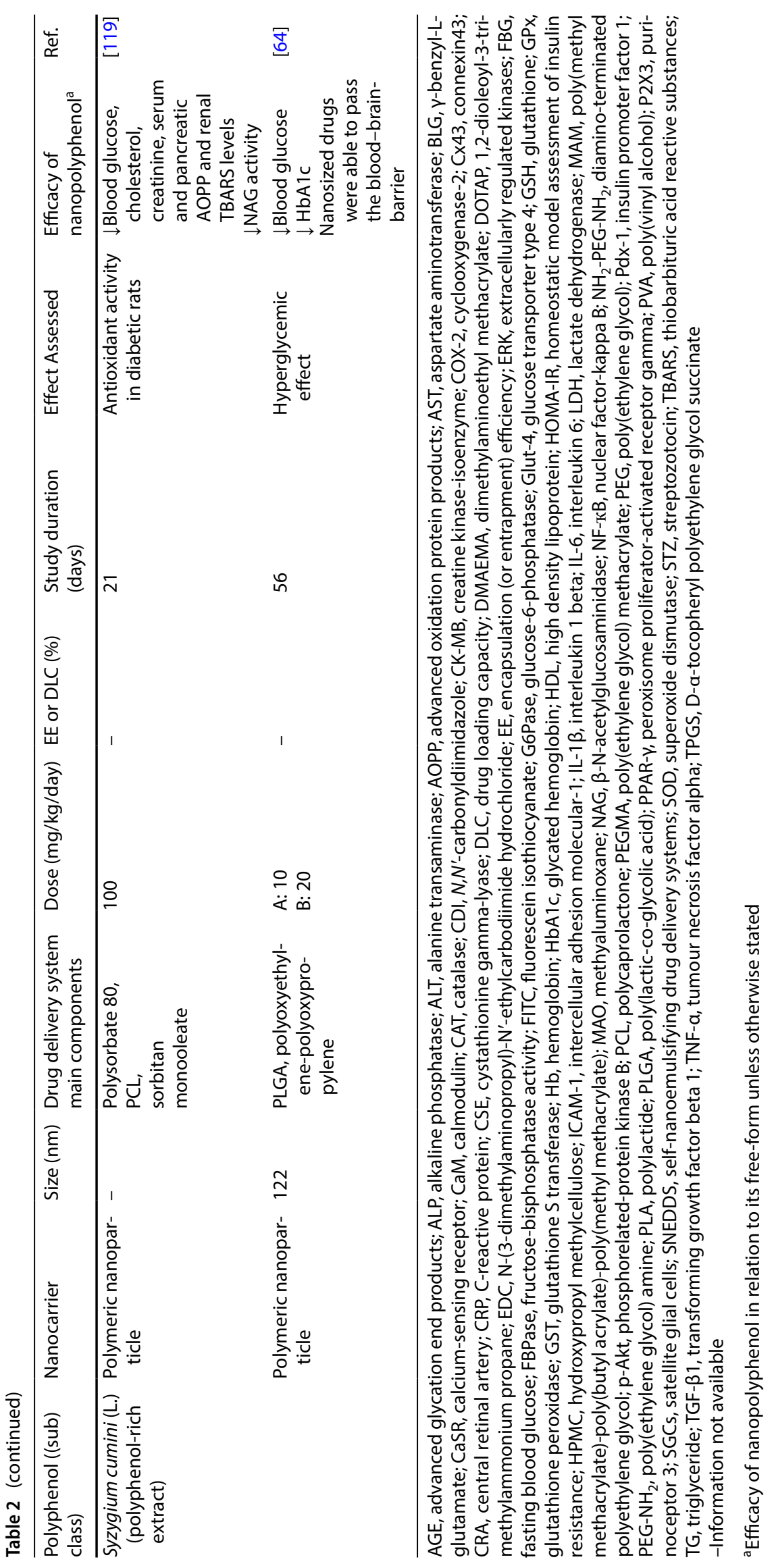

SN Applied Sciences

A SPRINGER NATURE journal 


\subsection{Phenolic acids}

Anti-diabetic effects of phenolic acids have been suggested in several studies [71]. Ferulic acid, which is a hydroxycinnamic acid, was nanoencapsulated and its impact on diabetic wound healing and hypoglycemia studied [72]. It was found that nanosized ferulic acid (with significantly increased sustained release) was able to promote wound healing significantly in diabetic rats compared to free-formed ferulic acid. This was effected through an increase in wound epithelization and hydroxyproline content. Hydroxyproline is a basic component of collagen. An increase in hydroxyproline content is an indication of increased cellular proliferation and therefore increased collagen synthesis [73]. This increase in collagen synthesis and turnover provides strength to repaired tissues and stimulates healing; thereby indicating the mechanism of action of the nanopolyphenol [74].

\subsection{Flavonoids}

There are 6 subclasses of compounds within the category of flavonoids as outlined in Fig. 2. Of these subclasses, included among the resulting 33 studies are flavanone $(n=1)$, flavones $(n=2)$, flavonols $(n=9)$ and one study which used a mixture of compounds from 2 different subclasses (flavonol and isoflavone) (Table 2). While the structures of these flavonoids are similar, structure-activity relationship causes changes to the chemical structure at particular regions to significantly impact functionality. The type of sugar moiety attached and the degree of hydroxylation and glycosylation (among other factors) can therefore influence the efficacy of the flavonoid [75]. This was corroborated by Sarian et al. [23] who outlined that the total number and configuration of hydroxyl groups existing on the compounds increased the antioxidant and anti-diabetic effects of flavonoids.

\subsubsection{Flavanone and flavone}

The flavanone studied was naringenin [76] while the flavones included baicalin and scutellarin $[77,78]$. A glucose lowering effect was obtained for naringenin and baicalin; however, scutellarin did not produce a similar effect in neither its free nor nanoencapsulated form. This effect of naringenin may be due to its ability to suppress the absorption of glucose from the intestine of diabetic rats [79]. While a hypoglycemic effect of scutellarin was not reported, in its nanoencapsulated form it caused an increase in cellular uptake and a two-threefold increase in bioavailability. Furthermore, the nanoencapsulated scutellarin also down-regulated both central retinal artery resistivity index and the expression of angiogenesis proteins which promote abnormal retinal blood vessel growth and contribute to diabetes-related vision loss. Other effects obtained for naringenin and baicalin included increasing and regenerating the structural complexity of Langerhans cells, and lowering glycated hemoglobin ( $\mathrm{HbA} 1 \mathrm{c})$; respectively.

\subsubsection{Flavonol}

Compounds studied among the flavonols included myricitrin, rutin and quercetin. While the effect of nanomyricitrin was not determined by comparison to its freeform, a clear increase in efficacy was seen with an increase in the concentration of the nanodrug [80]. The resulting outcomes included antioxidant and anti-diabetic effects which were evidenced by an increase in the activity of the endogenous antioxidant enzymes superoxide dismutase (SOD) and catalase (CAT); and through hypoglycemic effects. Nanoencapsulated rutin effectively improved wound contraction in diabetic foot ulcer rats by causing significant wound contraction when applied topically [81]. There was also increased antioxidants and hydroxyproline content in the rats treated with the nanoencapsulated drug compared to the rats treated with the free-form of the drug (on the 16th day). Oxidative stress is implicated in the progression of diabetic complications including diabetic foot ulcer and so an increase in antioxidants can reduce progression. Efficient regeneration of dermal tissues, capillary vessels and thickness of granulation tissues was also noted in rats treated with rutin nanoparticles.

Quercetin was the most researched flavonol with a total of 7 of the included 33 studies focusing on this polyphenol. The nanoencapsulated form of the drug varied between nanospheres, nanomicelle, nanorods, and nanoparticles. The effects of nanoquercetin were determined by comparison to its free-form in 5 studies [68, 70,82-84]. Of the remaining studies, one compared different concentrations of the nanoencapsulated drug [66], and in the other, the effects of the nanodrug were determined in treated versus untreated diabetic rats [62]. A decrease in glucose concentration was observed after administration of the nanoencapsulated quercetin in all instances. An increase in the activity of the endogenous antioxidant enzymes SOD, CAT and glutathione (GSH) was also obtained for several studies and this resulted in a concomitant reduction in oxidative stress $[62,66,82,83]$.

Accounts of other activities of nanoencapsulated quercetin included a decrease in aspartate transaminase (AST), alkaline phosphatase (ALP), alanine transaminase (ALT), glucose 6-phosphatase (G6Pase), fructose bisphosphatase (FBPase), downregulation of intercellular adhesion molecular-1 (ICAM-1) expression; amelioration of lipid peroxidation; and protein carbonylation $[62,70$, 
84]. The glucose metabolic enzymes G6Pase and FBPase, and the liver enzymes AST, ALP and ALT showed higher activity in diabetic subjects than their normoglycemic counterparts. Changes in the activity of liver enzymes can be a normal physiological phenomenon; however, it may also reflect potential liver injury [85]. Elevation of liver enzyme activity can be due to leakage of the enzymes from liver cytosol into the bloodstream due to hepatic injury. The administration of nanoquercetin restored the activities of both the glucose metabolic and liver enzymes towards normal via mechanisms including its radical scavenging abilities and also its ability to protect tissue function [62].

An improvement in memory performance and diabetic nephropathy by nanoquercetin were also communicated in one study each $[68,70]$. Oxidative stress plays a crucial role in the development of diabetes and is also involved in neuronal damage and cognitive decline [86]. Quercetin is able to confer antioxidant effects, due to the presence of two pharmacophores inside its structure, and thereby reduce oxidative stress [87]. Quercetin also reduces neuro-inflammation by inhibiting the NF-KB pathway and reducing pro-inflammatory cytokines such as tumor necrosis factor (TNF)- $\alpha$, interleukin (IL)- $1 \beta$, and IL- 6 which are associated with impaired cognition [88, 89]. Other properties of quercetin which enable its positive impact on memory performance include its ability to increase the expression of CAMP response element-binding protein (CREB) (since a reduction in the expression of this protein in the brain of diabetics can result in cognitive decline), and its inhibitory effects on acetylcholine esterase (AChE) which can result in cognitive dysfunction if induced in diabetic brains $[90,91]$.

As it relates to the effect of nanoquercetin on diabetic nephropathy, it was stated that the quercetin nanoparticle complex can attenuate diabetic nephropathy by down-regulating the expression level of ICAM-1 (which may play a role in the development of diabetes and diabetic nephropathy) on endothelium [70, 92]. Along with these therapeutic effects of nanoencapsulated quercetin, significant increase in bioavailability (of 1676\%) and significantly lower drug doses of the nanodrug produced greater effects than its free-form.

The isoflavonoid, puerarin, was administered in combination with rutin in the only study that used two different subclasses of polyphenols [69]. These compounds were able to demonstrate multiple anti-diabetic effects and increase pancreatic function and glucose utilization. These outcomes could be due to the previously outlined effects of rutin in addition to the ability of puerarin to elevate insulin expression and maintain metabolic homeostasis in STZ-diabetogenic mice [93].

\subsection{Non-flavonoids}

Polyphenols of a non-flavonoid classification were the subject of 19 of the 33 included studies. The groups of polyphenols included isoquinoline flavonoid $(n=3)$, flavanolignan $(n=1)$, stilbene $(n=1)$, diarylheptanoid $(n=11)$, anthraquinone $(n=1)$ and a crude polyphenol-rich extract $(n=2)$.

\subsubsection{Isoquinoline flavonoid, flavanolignan and stilbene}

The major pharmacological targets of the nanoencapsulated non-flavonoid polyphenols were the same as those of the nanoflavonoids outlined previously; that is, blood glucose levels, antioxidant status by determination of SOD, CAT and GSH levels, HbA1c, and the activity of the liver enzymes AST, ALT and ALP. The isoquinoline flavonoid (berberine) [65, 67, 94], the flavanolignan (sylibin) [95], and the stilbene (resveratrol) [96], impacted these pharmacological targets in a similar way as the flavonoids (Table 2). Additionally, nanoencapsulated berberine prepared in a nanostructured lipid carrier (NLC) and another which existed as a freeze dried nanoemulsion both resulted in increased oral bioavailability while the former also caused an increased sustained release. The berberine NLC was compared to both its free-form and a selenium-coated NLC berberine and a synergistic relationship was found between berberine and selenium.

\subsubsection{Diarylheptanoid}

The diarylheptanoid, curcumin, was the most studied nonflavonoid. Comparison of the effect of the nanoencapsulated polyphenol was done with the polyphenol-void nanocarrier, other bioactives/pharmaceuticals, and also with its free-form. The biological effects and conditions assessed included anti-diabetic and antioxidant activity $[63,97,98]$, diabetic neuropathic pain $[99,100]$, diabetic cardiomyopathy [101, 102], inflammation [103-105], and cataract in a diabetic rat model [106]. It was reported that nanoencapsulated curcumin produced anti-diabetic effects by increasing the number of insulin positive cells and the gene expression of insulin, alleviating STZ-induced $\beta$-cell damage and increasing the upregulation of the transcription factors pancreatic and duodenal homeobox 1 $(\mathrm{Pdx}-1)$, which play a critical role in pancreatic development, and NKx6.1 which is required for the development of $\beta$-cells $[97,98]$. One possible mechanism through which these effects could have been produced include curcumin inhibiting phosphodiesterases (PDEs) which degrade cyclic adenosine monophosphate (CAMP) [107]. 
This allows for the intracellular production of cAMP and a consequent enhancement of pancreatic $\beta$-cell function and insulin secretion.

Nanocurcumin produced desirable results against diabetic neuropathic pain by decreasing the upregulated IL-1 $\beta$ and connexin43 (Cx43) expression, decreasing phosphorylated-protein kinase $B$ ( $p$-Akt), decreasing the upregulation of the $\mathrm{P} 2 \mathrm{Y} 12$ receptor on satellite glial cells (SGCs), decreasing neuro-inflammation and increasing antioxidant defence $[99,100]$. The upregulated expression of IL-1 $\beta$ and $C x 43$ contributes to the induction and/ or maintenance of pain $[108,109]$. The impact of nanoencapsulated curcumin on these proteins explains possible mechanisms through which neuropathic pain can be reduced. P2Y12 and p-Akt are involved in the initiation and maintenance of neuropathic pain $[110,111]$. A reduction of their activity therefore alleviates pain.

The effect of nanocurcumin on diabetic cardiomyopathy was evidenced through a reduction in AST. There were however non-significant effects on glucose and insulin compared to untreated diabetic rats [102]. Increases in the following parameters were also reported: hydrogen sulfide $\left(\mathrm{H}_{2} \mathrm{~S}\right), \mathrm{CaSR}, \mathrm{CSE}$ and CaM [101]. Diabetic cardiomyopathy is a type of cardiovascular damage in diabetic patients that is independent of the coexistence of ischemic heart disease or hypertension. Damage to the heart muscle enhances the release of AST in diabetic subjects; therefore, a reduction in AST by nanocurcumin is indicative of a positive effect. Intracellular calcium is involved in several vital biochemical processes and an increase in its concentration can enhance the activity of CaM and regulate a variety of physiological functions. In turn, $\mathrm{Ca}^{2+} / \mathrm{CaM}$ can regulate the activity of CSE and the formation of $\mathrm{H}_{2} \mathrm{~S}$ [102]. Exogenous $\mathrm{H}_{2} \mathrm{~S}$ improves cardiac function and attenuates cardiac hypertrophy and myocardial fibrosis in diabetic mice via the forkhead box protein 01 (FOXO1) pathway [112]. This protein plays important roles in the regulation of gluconeogenesis and glycogenolysis by insulin signaling; hence, by increasing exogenous $\mathrm{H}_{2} \mathrm{~S}$, protective effects against diabetic cardiomyopathy are attained.

For the studies which assessed the anti-inflammatory effects of nanoencapsulated curcumin [103-105], the drug showed strong anti-inflammatory effects by inhibiting C-reactive protein (CRP), IL- 6 and TNF-a release. Nanocurcumin also ameliorated negative changes in NF-KB (which plays a role in many inflammatory processes), hepatic COX-2 (an enzyme responsible for inflammation), and hepatic peroxisome proliferator activated receptor (PPAR) $-\gamma$ (which inhibits the expression of inflammatory cytokines), while lowering 8-oxo-20-deoxyguanosine [113]. This oxidized derivative of deoxyguanosine is a biomarker of oxidative damage and its concentrations are elevated in diabetic subjects. A reduction of this clinical marker by nanocurcumin is therefore an indication of antidiabetic effects.

The efficacy of curcumin nanoparticles in delaying diabetes-induced cataract in rats was the focus of one study [106]. Efficacy was determined by comparing the activity of the nanoencapsulated drug to its free-form. It was communicated that both the nano and free-form of curcumin failed to reduce glucose and increase insulin levels; however, an effect against osmotic stress caused by hyperglycemia was observed. A delay in the progression of diabetic cataract was also attributed to the ability of nanocurcumin to mediate the biochemical pathways of disease progression such as protein insolubilization, the polyol pathway (a contributor to diabetic retinopathy), protein glycation, and crystallin distribution.

\subsubsection{Anthraquinone}

The sole anthraquinone polyphenol reported among the included studies was emodin [114]. Nanoencapsulated emodin was assessed for its effect against diabetic neuropathic pain. The effects reported include a decrease in the upregulation of purinoceptor 3 (P2X3) receptor and TNF-a protein, and a reduction of the phosphorylation and activation of extracellular signal-regulated protein kinases 1 and 2 (ERK1/2). A reduction in the activity of these proteins result in a decline in diabetic neuropathic pain since P $2 X 3$ is involved in acute, inflammatory, neuropathic, visceral and cancer pain; TNF-a plays a role in the peripheral mediation of neuropathic pain; and ERK (which are activated in spinal glial cells and lead to the synthesis of proinflammatory/pronociceptive mediators) can enhance and prolong pain [115-117]. There are other studies, however, for which different roles have been reported for ERK1/2. These include controlling the phosphorylation and protein level of CREB and positively impacting glucose-mediated $\beta$-cell survival [118]. Given these roles, a reduction of ERK $1 / 2$ could therefore influence the negative effect of nanocurcumin on glucose and insulin levels.

\subsubsection{Crude polyphenol extract}

The crude polyphenol extract of java plums was nanoencapsulated and their antioxidant and hypoglycemic effects determined $[64,119]$. Compared to the free-form of the drug, it was found that the polymeric nanoparticles were able to effect changes in lowering blood glucose, cholesterol, creatinine, serum and pancreatic advanced oxidation protein products (AOPP). Additionally, there were reductions in renal thiobarbituric acid reactive substances (TBARS) levels, $\beta$-N-acetylglucosaminidase (NAG) activity and $\mathrm{HbA} 1 \mathrm{c}$, and nanosized drugs were able to pass the blood-brain-barrier. 


\section{Discussion}

Polyphenols are ubiquitous in nature and have numerous proposed health benefits. The low bioavailability of polyphenols however poses a great challenge in their therapeutic efficacy. Nanotechnology has proved to be a promising field which can allay these challenges by improving bioavailability and allowing for targeted drug delivery and sustained drug release while lowering the required drug dose. The utilization of nanotechnology potentiates the beneficial effects of polyphenols in diabetes treatment in vivo via several mechanisms. Of the 24 studies that compared the activity of the nanoencapsulated polyphenol to its free-form, it was found that effects were significantly greater for the former in all but one study [68] where similar effects were reported for both forms of the drug for selected parameters and in two other instances where both forms failed to reduce blood glucose concentrations [78, 106].

The polyphenols studied were found to be effective as hypoglycemic, anti-hyperglycemic, anti-diabetic and antioxidant agents while also producing positive effects in diabetic wound-healing, diabetic neuropathic pain, diabetic retinopathy and cataract, diabetic nephropathy, diabetic cardiomyopathy, and diabetes-induced learning and memory impairment.

There were great variations among the type of polyphenol, the nanocarrier and nanoencapsulation technique used, the size of the nanomaterials, the drug delivery system, the dose of nanopolyphenol administered, the encapsulation efficiency and loading capacity of the resulting nanomaterials and the study duration. With these variations, superior anti-diabetic effects of the nanopolyphenols were still evident in all but 4 of the 33 included studies $[68,78,101,106]$. Of these 4 studies, 3 compared the efficacy of the nanodrug to its freeform while the other did a comparison with untreated diabetic rats.

The design of a suitable drug delivery system requires the properties of the polyphenol to be taken into consideration. Different polyphenol subgroups can differ significantly in chemical stability [2]. Resveratrol, for example, is sensitive to $\mathrm{pH}$, and so degradation increases significantly above $\mathrm{pH} 6.8$ [120] while the highest degradation of quercetin is at $\mathrm{pH} 2$ at $60^{\circ} \mathrm{C}$ [121]. The processing conditions and environment are therefore dependent on sound knowledge of the polyphenols to ensure their efficacy is unaltered.

The variations seen in the drug delivery systems used are of note due to the integral role they play in the advancement of drug delivery technology and the fact that they are tailored to exert distinct biological functions [122]. Environmentally-responsive polymers, or smart polymers, are a class of materials composed of a diversity of linear and branched (co)polymers or cross-linked polymer networks that are able to undergo a dramatic physical or chemical change in response to an external stimulus [123]. The polymeric systems can be activated by physical stimuli (such as temperature, ultrasound, light, and magnetic and electrical fields) or chemical stimuli (such as $\mathrm{pH}$, redox potential, ionic strength, and chemical agents) and these systems have been the focus of several research $[40,123]$.

Depending on the type of external stimuli, that is, whether physical or chemical, the effect induced on the polymer system can directly modulate the energy level of the polymer/solvent system and induce a polymer response at some critical energy level or it can induce a response by altering molecular interactions between polymer and solvent or between polymer chains, respectively. The resulting behavioral change on the polymer system can include transitions in solubility, hydrophilic-hydrophobic balance, and conformation [124]. The majority of responsive polymers for drug delivery can be broadly categorized as hydrogels, micelles, polyplexes, or polymerdrug conjugates [123]. Of the drug delivery systems outlined in Table 2, there were two nanomicelles and several polymer-drug conjugates with great variations among the latter. While PEG is not a smart polymer, it can be grafted with other polymers such as poly(methacrylic acid) to form a responsive-polymer [123, 125]. Two more popular responsive polymers are polyacrylic acid (PAA) (carbopol) which was used in one of the included study and is a $\mathrm{pH}$ sensitive smart polymer; and the commercially available Pluronic (non-proprietary name "poloxamer") which is a nonionic tri-block copolymer consisting of a central hydrophobic polypropylene oxide (PPO) block flanked by hydrophilic polyethylene oxide (PEO) blocks; that is, PEO-PPOPEO [126]. Pluronics were used in seven of the included studies, as outlined in Table 2, and are temperature sensitive smart polymers. All studies that used a smart polymer reported positive results. The mechanism of action of different types of smart polymers however varies and since their physical and chemical properties impact their utilization, care should be taken in selecting a suitable one.

\subsection{Challenges and future prospects}

The application of nanotechnology in medicine can significantly impact human health as it relates to the prevention, diagnosis, and treatment of diseases. The use of this technology aims to increase therapeutic efficacy, decrease the therapeutically effective dose, and/or reduce the risk of systemic side effects. Achieving these outcomes however present several challenges. These can be categorized 
as biological challenges, challenges associated with biocompatibility and safety, large-scale manufacturing, intellectual property (IP), government regulations, and overall cost-effectiveness in comparison to current therapies [127].

Some challenges associated with the biological properties, biocompatibility and safety of nanopolyphenols include inadequate understanding of the interaction of nanomaterials with tissues and cells, limited understanding of the biological interaction of these materials with the biological environment in the body of patients, inadequate information on the degree of accumulation of nanomedicines in target organs, tissues, and cells, the need for the development of more specialized toxicological studies for nanomedicines, and required structural stability of the nanomaterials following in vivo administration $[127,128]$. Potential challenges arising from the large-scale manufacture of nanopolyphenols and the cost-effectiveness of their production include difficulties in their large-scale production according to GMP standards to ensure quality control and reproducibility in physicochemical properties on a batch-to-batch basis [129]. Additionally, the cost of the raw materials involved in the synthesis of nanopolyphenols are also obstacles for their scale-up and manufacture. In order to compensate for the high costs of the development and manufacture of these nanomedicine products, the clinical therapeutic effect of the drugs has to be much more advanced than conventional therapeutics [128]. Intellectual property and government regulation associated challenges include a lack of clear regulatory guidelines specific for nanoparticulate nanomedicines, and the complexity of nanomedicine patents and IP [127].

Approaches to use nanotechnology in the particle design and formulation of nanomedicines derived from polyphenols are beginning to expand the nutraceutical and pharmaceutical markets. These growing nanomedicine industries are expected to have a significant impact on the economy and medical care of the society. Currently, nanomedicines are used unanimously to improve the lives of patients suffering from a number of illnesses and this review has outlined the efficacy of nanopolyphenols as anti-diabetic agents. The safety of these drug delivery systems is therefore critical. Presently, a significant number of research has been conducted using smart polymers in the synthesis of nanopolyphenols. Smart polymers that have been approved by the US Food and Drug Administration as a safe drug delivery system (e.g. Pluronics ${ }^{\circ}$ ) should be carefully selected and used in the design of nanomaterials. Most of the polymers used in the drug delivery systems of the included studies are synthetic in origin and while their short-term use in vivo is regarded as being safe and non-toxic, the effect of prolonged exposure of large quantities in human subjects is not known [130]. Nanomaterials which are comprised of inorganic species are also of concern as it relates to possible toxic effects. Self-carrying nanodrug delivery systems which functionalize the nanocarrier by utilizing the polyphenol as the nanocarrier would eliminate the possibility of toxicity from a nanocarrier and should therefore be further explored.

\section{Conclusion}

The nanoencapsulation of polyphenols can be achieved using polymeric, vesicular or inorganic nanocarriers. Several physical, chemical, physicochemical and a few other nanoencapsulation techniques are also available. The groups of polyphenols studied included phenolic acids (hydroxycinnamic acid), flavonoids (flavonol, flavone, flavanone and isoflavone) and non-flavonoids (isoquinoline flavonoid, flavanolignan, stilbene, diarylheptanoid and anthraquinone). The most studied polyphenols were the flavonol, quercetin, and the diarylheptanoid, curcumin. Anti-diabetic effects were noted for all groups of polyphenols and several studies reported significantly higher effects for the nanopolyphenol compared to its free-form.

It can be concluded that the diversity of processes involved in the manufacture and analysis of nanopolyphenols impacts them differently. This in turn influences their physical nature, chemical behavior, biological interactions, analytical properties and efficacy which consequently may introduce some constraints to their applications. With a deeper understanding of the physicochemical properties of polyphenols, the use of smart polymers in the development of cost-effective and efficient self-carrying nanodrug delivery systems, and the stabilization of nanomaterials to facilitate site-specific targeting, nanoencapsulated polyphenols can play a critical role in the push towards safer and more effective therapeutics to counter the rise of lifestyle diseases.

Acknowledgements Open access funding provided by Umea University. The sole author had responsibility for all parts of the manuscript. Gratitude is extended to Professor Anna Nördstrom of Umeå University, Sweden, for reviewing the manuscript.

Funding Research generously supported by the Kempe Foundation (SMK-1870). The funder played no role in the design, implementation, analysis or interpretation of the data.

\section{Compliance with ethical standards}

Conflict of interest The author reports no conflicts of interest in this work.

Open Access This article is licensed under a Creative Commons Attribution 4.0 International License, which permits use, sharing, adaptation, distribution and reproduction in any medium or format, as 
long as you give appropriate credit to the original author(s) and the source, provide a link to the Creative Commons licence, and indicate if changes were made. The images or other third party material in this article are included in the article's Creative Commons licence, unless indicated otherwise in a credit line to the material. If material is not included in the article's Creative Commons licence and your intended use is not permitted by statutory regulation or exceeds the permitted use, you will need to obtain permission directly from the copyright holder. To view a copy of this licence, visit http://creativecommons .org/licenses/by/4.0/.

\section{References}

1. Sudjaroen $Y$ (2009) Plant-derived phenolic antioxidants and cancer prevention. Thai Cancer J 29(9):126-134

2. Tsao R (2010) Chemistry and biochemistry of dietary polyphenols. Nutrients 2(12):1231-1246. https://doi.org/10.3390/ nu2121231

3. Scalbert A, Williamson G (2000) Dietary intake and bioavailability of polyphenols. Nutr J 130(8):2073S-2085S. https://doi. org/10.1093/jn/130.8.2073s

4. Cook NC, Samman S (1996) Flavonoids-chemistry, metabolism, cardioprotective effects, and dietary sources. J Nutr Biochem 7(2):66-76. https://doi.org/10.1016/S0955-2863(95)00168-9

5. Ndhlala AR, Moyo M, Van Staden J (2010) Natural antioxidants: fascinating or mythical biomolecules? Molecules 15(10):69056930. https://doi.org/10.3390/molecules 15106905

6. Puupponen-Pimia R, Nohynek L, Alakomi HL, Oksman-Caldentey KM (2005) Bioactive berry compounds-novel tools against human pathogens. Appl Microbiol Biotechnol 67(1):8-18. https ://doi.org/10.1007/s00253-004-1817-x

7. Campbell TF, McKenzie J, Murray J, Delgoda R, Bowen-Forbes CS (2017) Rubus rosifolius varieties as antioxidant and potential chemopreventive agents. J Funct Foods 37:49-57. https://doi. org/10.1016/j.jff.2017.07.040

8. Den Hartogh JD, Tsiani E (2019) Antidiabetic properties of naringenin: a citrus fruit polyphenol. Biomolecules. https://doi. org/10.3390/biom9030099

9. Zygmunt K, Faubert B, MacNeil J, Tsiani E (2010) Naringenin, a citrus flavonoid, increases muscle cell glucose uptake via AMPK. Biochem Biophys Res Commun 398(2):178-183. https ://doi.org/10.1016/j.bbrc.2010.06.048

10. Kim Y, Keogh JB, Clifton PM (2016) Polyphenols and glycemic control. Nutrients 8(1):17. https://doi.org/10.3390/nu8010017

11. Loureiro G, Martel F (2019) The effect of dietary polyphenols on intestinal absorption of glucose and fructose: relation with obesity and type 2 diabetes. Food Rev Int 35:1-17. https://doi. org/10.1080/87559129.2019.1573432

12. Li C, Li X, Han H, Cui H, Peng M, Wang G, Wang Z (2016) Effect of probiotics on metabolic profiles in type 2 diabetes mellitus: a meta-analysis of randomized, controlled trials. Medicine 95(26):e4088. https://doi.org/10.1097/md.0000000000004088

13. Varghese SM, Thomas J (2019) Polyphenolic constituents in mulberry leaf extract (M. latifolia L. Cv BC259) and its antidiabetic effect in streptozotocin induced diabetic rats. Pak J Pharm Sci 32(1):69-74

14. Mollace V, Scicchitano M, Paone S, Casale F, Calandruccio $C$, Gliozzi M, Musolino V, Carresi C, Maiuolo J, Nucera S, Riva A, Allegrini P, Ronchi M, Petrangolini G, Bombardelli E (2019) Hypoglycemic and hypolipemic effects of a new lecithin formulation of bergamot polyphenolic fraction: a double blind, randomized, placebo- controlled study. Endocr Metab Immune Disord Drug Targets 19(2):136-143. https://doi.org/10.2174/18715 30319666181203151513
15. Yang L, Ling W, Yang Y, Chen Y, Tian Z, Du Z, Chen J, Xie Y, Liu $Z$, Yang $L$ (2017) Role of purified anthocyanins in improving cardiometabolic risk factors in Chinese men and women with prediabetes or early untreated diabetes: a randomized controlled trial. Nutrients. https://doi.org/10.3390/nu9101104

16. D'Archivio M, Filesi C, Varì R, Scazzocchio B, Masella R (2010) Bioavailability of the polyphenols: status and controversies. Int J Mol Sci 11(4):1321-1342. https://doi.org/10.3390/ijms1 1041321

17. Bohn T (2014) Dietary factors affecting polyphenol bioavailability. Nutr Rev. https://doi.org/10.1111/nure.12114

18. Oracz J, Nebesny E, Zyzelewicz D, Budryn G, Luzak B (2019) Bioavailability and metabolism of selected cocoa bioactive compounds: a comprehensive review. Crit Rev Food Sci Nutr. https://doi.org/10.1080/10408398.2019.1619160

19. Maeda-Yamamoto M, Ema K, Tokuda Y, Monobe M, Tachibana H, Sameshima Y, Kuriyama S (2011) Effect of green tea powder (Camellia sinensis L. cv. Benifuuki) particle size on O-methylated EGCG absorption in rats; The Kakegawa Study. Cytotechnology 63(2):171-179. https://doi.org/10.1007/ s10616-010-9331-8

20. Aguirre A, Borneo R (2019) Improving bioavailability of polyphenols using nanodelivery systems based on food polymers. In: Watson RR (ed) Polyphenols in plants, 2nd edn. Academic Press, Cambridge, pp 59-65. https://doi.org/10.1016/ B978-0-12-813768-0.00004-9

21. Ajebli M, Eddouks M (2019) The promising role of plant tannins as bioactive antidiabetic agents. Curr Med Chem 26(25):4852-4884. https://doi.org/10.2174/0929867325 666180605124256

22. Vinayagam $R$, Jayachandran M, Xu B (2016) Antidiabetic effects of simple phenolic acids: a comprehensive review. Phytother Res 30(2):184-199. https://doi.org/10.1002/ptr.5528

23. Sarian MN, Ahmed QU, Mat So'ad SZ, Alhassan AM, Murugesu S, Perumal V, Syed Mohamad SNA, Khatib A, Latip J (2017) Antioxidant and antidiabetic effects of flavonoids: a structure-activity relationship based study. Biomed Res Int 2017:8386065. https ://doi.org/10.1155/2017/8386065

24. Pan A, Sun J, Chen Y, Ye X, Li H, Yu Z, Wang Y, Gu W, Zhang $X$, Chen X, Demark-Wahnefried W, Liu Y, Lin X (2007) Effects of a flaxseed-derived lignan supplement in type 2 diabetic patients: a randomized, double-blind, cross-over trial. PLoS ONE 2(11):e1148-e1148. https://doi.org/10.1371/journ al.pone.0001148

25. Oyenihi OR, Oyenihi AB, Adeyanju AA, Oguntibeju OO (2016) Antidiabetic effects of resveratrol: the way forward in its clinical utility. J Diabetes Res 2016:9737483. https://doi. org/10.1155/2016/9737483

26. Earnest E, Lawrence E, llevbare F, Okparume Daniel (2013) The roles of Capsicum in diabetes mellitus. J Pharmacol Toxicol Res 6(1):22-27. https://doi.org/10.5707/cjptres.2013.6.1.22.27

27. Zadernowski R, Naczk M, Nesterowicz J (2005) Phenolic acid profiles in some small berries. J Agric Food Chem 53(6):21182124. https://doi.org/10.1021/jf040411p

28. Lee J, Dossett M, Finn CE (2012) Rubus fruit phenolic research: the good, the bad, and the confusing. Food Chem 130(4):785796. https://doi.org/10.1016/j.foodchem.2011.08.022

29. Puupponen-Pimia R, Nohynek L, Meier C, Kahkonen M, Heinonen M, Hopia A, Oksman-Caldentey KM (2001) Antimicrobial properties of phenolic compounds from berries. J Appl Microbiol 90(4):494-507. https://doi.org/10.104 6/j.1365-2672.2001.01271.x

30. Szajdek A, Borowska EJ (2008) Bioactive compounds and health-promoting properties of berry fruits: a review. Plant Foods Hum Nutr 63(4):147-156. https://doi.org/10.1007/s1113 0-008-0097-5 
31. Lampe JW (2003) Isoflavonoid and lignan phytoestrogens as dietary biomarkers. Nutr J 133(3):956S-964S. https://doi. org/10.1093/jn/133.3.956S

32. Akinwumi BC, Bordun KM, Anderson HD (2018) Biological activities of stilbenoids. Int J Mol Sci. https://doi.org/10.3390/ ijms 19030792

33. Jeevanandam J, Barhoum A, Chan YS, Dufresne A, Danquah MK (2018) Review on nanoparticles and nanostructured materials: history, sources, toxicity and regulations. Beilstein J Nanotechnol 9:1050-1074. https://doi.org/10.3762/bjnan 0.9 .98

34. Augustin MA, Hemar Y (2009) Nano- and micro-structured assemblies for encapsulation of food ingredients. Chem Soc Rev 38(4):902-912. https://doi.org/10.1039/b801739p

35. Couvreur P, Dubernet C, Puisieux F (1995) Controlled drug delivery with nanoparticles: current possibilities and future trends. Eur J Pharm Biopharm 41(1):2-13

36. Jyothi NVN, Prasanna PM, Sakarkar SN, Prabha KS, Ramaiah PS, Srawan GY (2010) Microencapsulation techniques, factors influencing encapsulation efficiency. J Microencapsul 27(3):187-197

37. Cano-Sarabia M, Maspoch D (2014) Nanoencapsulation. In: Bhushan B (ed) Encyclopedia of nanotechnology. Springer, Dordrecht, pp 1-16. https://doi. org/10.1007/978-94-007-6178-0_50-2

38. Abou-Hamad E, Kim Y, Wagberg T, Boesch D, Aloni S, Zettl A, Rubio A, Luzzi DE, Goze-Bac C (2009) Molecular dynamics and phase transition in one-dimensional crystal of $C(60)$ encapsulated inside single wall carbon nanotubes. ACS Nano 3(12):3878-3883. https://doi.org/10.1021/nn901128t

39. Zou Y, Liu B, Wang L, Liu D, Yu S, Wang P, Wang T, Yao M, Li Q, Zou B, Cui T, Zou G, Wagberg T, Sundqvist B, Mao HK (2009) Rotational dynamics of confined C60 from near-infrared Raman studies under high pressure. Proc Natl Acad Sci USA 106(52):22135-22138. https://doi.org/10.1073/pnas.09119 63106

40. James HP, John R, Alex A, Anoop KR (2014) Smart polymers for the controlled delivery of drugs: a concise overview. Acta Pharm Sin B 4(2):120-127. https://doi.org/10.1016/j. apsb.2014.02.005

41. Vauthier C, Bouchemal K (2009) Methods for the preparation and manufacture of polymeric nanoparticles. Pharm Res 26(5):1025-1058. https://doi.org/10.1007/s11095-008-9800-3

42. Nagavarma BVN, Yadav H, Ayaz A, Vasudha L, Shivakumar $H$ (2012) Different techniques for preparation of polymeric nanoparticles: a review. Asian J Pharm Clin Res 5:16-23

43. Efthimiadou EK, Theodosiou M, Toniolo G, Abu-Thabit NY (2018) Stimuli-responsive biopolymer nanocarriers for drug delivery applications. In: Makhlouf ASH, Abu-Thabit NY (eds) Stimuli responsive polymeric nanocarriers for drug delivery applications, vol 1. Woodhead Publishing, Cambridge, pp 405-432. https://doi.org/10.1016/B978-0-08-101997-9.00019-9

44. Anwunobi A, Emeje M (2011) Recent applications of natural polymers in nanodrug delivery. J Nanomedic Nanotechnol 4:2. https://doi.org/10.4172/2157-7439.s4-002

45. Muhamad I, Selvakumaran S, Lazim NA (2014) Designing polymeric nanoparticles for targeted drug delivery system. In: Seifalian A, de Mel A, Kalaskar DM (eds) Nanomedicine. One Central Press (OCP), Manchester, pp 287-311

46. Young CJ, Poole-Warren LA, Martens PJ (2012) Combining submerged electrospray and UV photopolymerization for production of synthetic hydrogel microspheres for cell encapsulation. Biotechnol Bioeng 109(6):1561-1570

47. Olabisi RM (2015) Cell microencapsulation with synthetic polymers. J Biomed Mater Res A 103(2):846-859. https://doi. org/10.1002/jbm.a.35205
48. Saw PE, Lee $S$, Jon $S$ (2019) Naturally occurring bioactive compound-derived nanoparticles for biomedical applications. Adv Ther. https://doi.org/10.1002/adtp.201800146

49. Crespy D, Lv L-P, Landfester K (2016) Redefining the functions of nanocapsule materials. Nanoscale Horiz. https://doi. org/10.1039/C5NH00112A

50. Safavy A, Raisch KP, Mantena S, Sanford LL, Sham SW, Krishna NR, Bonner JA (2007) Design and development of water-soluble curcumin conjugates as potential anticancer agents. J Med Chem 50(24):6284-6288. https://doi.org/10.1021/jm700988f

51. Tang H, Murphy CJ, Zhang B, Shen Y, Sui M, Van Kirk EA, Feng X, Murdoch WJ (2010) Amphiphilic curcumin conjugate-forming nanoparticles as anticancer prodrug and drug carriers: in vitro and in vivo effects. Nanomedicine 5(6):855-865. https://doi. org/10.2217/nnm.10.67

52. Assadpour E, Jafari SM (2019) Nanoencapsulation: techniques and developments for food applications. In: López Rubio A, Fabra Rovira MJ, Martínez Sanz M, Gómez-Mascaraque LG (eds) Nanomaterials for food applications. Elsevier, Amsterdam, pp 35-61. https://doi.org/10.1016/B978-0-12-814130-4.00003-8

53. Jain AK, Thareja S (2019) In vitro and in vivo characterization of pharmaceutical nanocarriers used for drug delivery. Artif Cells Nanomed Biotechnol 47(1):524-539. https://doi. org/10.1080/21691401.2018.1561457

54. Chen S, Hao X, Liang X, Zhang Q, Zhang C, Zhou G, Shen S, Jia G, Zhang J (2016) Inorganic nanomaterials as carriers for drug delivery. J Biomed Nanotechnol 12(1):1-27. https://doi. org/10.1166/jbn.2016.2122

55. Naseri N, Valizadeh H, Zakeri-Milani P (2015) Solid lipid nanoparticles and nanostructured lipid carriers: structure, preparation and application. Adv Pharm Bull 5(3):305-313. https://doi. org/10.15171/apb.2015.043

56. Suganya V, Anuradha V (2017) Microencapsulation and nanoencapsulation: a review. IJPCR. https://doi.org/10.25258/ijpcr .v9i3.8324

57. Ezhilarasi P, Chhanwal N, Chinnaswamy A (2013) Nanoencapsulation techniques for food bioactive components: a review. Food Bioproc Technol 6:628-647. https://doi.org/10.1007/ s11947-012-0944-0

58. Neamtu I, Rusu AG, Diaconu A, Nita LE, Chiriac AP (2017) Basic concepts and recent advances in nanogels as carriers for medical applications. Drug Deliv 24(1):539-557. https://doi. org/10.1080/10717544.2016.1276232

59. Varma M, Kaushal A, Garg A, Garg S (2004) Factors affecting mechanism and kinetics of drug release from matrix-based oral controlled drug delivery systems. Am J Adv Drug Deliv 2:43-57. https://doi.org/10.2165/00137696-200402010-00003

60. Stefaniak A (2017) Principal metrics and instrumentation for characterization of engineered nanomaterials. In: Mansfield E, Kaiser DL, Fujita D, Van de Voorde M (eds) Metrology and standardization for nanotechnology: protocols and industrial innovations. Wiley-VCH, Weinheim, pp 151-174

61. Jafari SM, Esfanjani AF (2017) Instrumental analysis and characterization of nanocapsules. In: Jafari SM (ed) Nanoencapsulation technologies for the food and nutraceutical industries. Academic Press, Cambridge, pp 524-544

62. Alam MM, Abdullah K, Singh B, Naqvi A, Naseem I (2016) Ameliorative effect of quercetin nanorods on diabetic mice: mechanistic and therapeutic strategies. RSC Adv 6:55092-55103. https://doi.org/10.1039/C6RA04821H

63. Potphode N, Daunde J, Desai S, Walvekar M (2018) Nanocurcumin: a potent enhancer of body antioxidant system in diabetic mice. Int J Phytomed 10(3):162-167

64. Samadder A, Das S, Das J, Paul A, Khuda-Bukhsh AR (2012) Ameliorative effects of Syzygium jambolanum extract and its poly (lactic-co-glycolic) acid nano-encapsulated form on 
arsenic-induced hyperglycemic stress: a multi-parametric evaluation. J Acupunct Meridian Stud 5(6):310-318. https:// doi.org/10.1016/j.jams.2012.09.001

65. Xue M, Yang MX, Zhang W, Li XM, Gao DH, Ou ZM, Li ZP, Liu SH, Li XJ, Yang SY (2013) Characterization, pharmacokinetics, and hypoglycemic effect of berberine loaded solid lipid nanoparticles. Int J Nanomed 8:4677-4687. https://doi.org/10.2147/ijn. S51262

66. Abd El-Rahman SN, Al-Jameel SS (2017) Synergistic effect of quercetin nanoparticles on liver and pancreas tissues and oxidative stress of streptozotocin-induced diabetic rats. Asian J Chem 29(5):1003-1010. https://doi.org/10.14233/ajche m.2017.20389

67. Yin J, Hou Y, Yin Y, Song X (2017) Selenium-coated nanostructured lipid carriers used for oral delivery of berberine to accomplish a synergic hypoglycemic effect. Int J Nanomed 12:86718680. https://doi.org/10.2147/ijn.S144615

68. Ebrahimpour S, Esmaeili A, Beheshti S (2018) Effect of quercetin-conjugated superparamagnetic iron oxide nanoparticles on diabetes-induced learning and memory impairment in rats. Int J Nanomed 13:6311-6324. https://doi.org/10.2147/ijn.S177871

69. Deng W, Wang H, Wu B, Zhang X (2019) Selenium-layered nanoparticles serving for oral delivery of phytomedicines with hypoglycemic activity to synergistically potentiate the antidiabetic effect. Acta Pharm Sin B 9(1):74-86. https://doi.org/10.1016/j. apsb.2018.09.009

70. Tong F, Liu S, Yan B, Li X, Ruan S, Yang S (2017) Quercetin nanoparticle complex attenuated diabetic nephropathy via regulating the expression level of ICAM-1 on endothelium. Int J Nanomed 12:7799-7813. https://doi.org/10.2147/ijn.S146978

71. Jung EH, Ran Kim S, Hwang IK, Youl Ha T (2007) Hypoglycemic effects of a phenolic acid fraction of rice bran and ferulic acid in C57BL/KsJ-db/db mice. J Agric Food Chem 55(24):9800-9804. https://doi.org/10.1021/jf0714463

72. Bairagi U, Mittal P, Singh J, Mishra B (2018) Preparation, characterization, and in vivo evaluation of nano formulations of ferulic acid in diabetic wound healing. Drug Dev Ind Pharm 44(11):1783-1796

73. Ricard-Blum S, Ruggiero FJPB (2005) The collagen superfamily: from the extracellular matrix to the cell membrane. Pathol Biol (Paris) 53(7):430-442

74. Nissinen LM, Kahari VM (2015) Collagen turnover in wound repair: a macrophage connection. J Invest Dermatol 135(10):2350-2352. https://doi.org/10.1038/jid.2015.246

75. Wang H, Cao G, Prior RL (1997) Oxygen radical absorbing capacity of anthocyanins. J Agric Food Chem 45(2):304-309. https://doi.org/10.1021/jf960421t

76. Maity S, Mukhopadhyay P, Kundu PP, Chakraborti AS (2017) Alginate coated chitosan core-shell nanoparticles for efficient oral delivery of naringenin in diabetic animals: an in vitro and in vivo approach. Carbohydr Polym 170:124-132

77. Shi F, Wei Z, Zhao Y, Xu X (2016) Nanostructured lipid carriers loaded with baicalin: an efficient carrier for enhanced antidiabetic effects. Pharmacogn Mag 12(47):198-202. https://doi. org/10.4103/0973-1296.186347

78. Wang J, Tan J, Luo J, Huang P, Zhou W, Chen L, Long L, Zhang LM, Zhu B, Yang L, Deng DY (2017) Enhancement of scutellarin oral delivery efficacy by vitamin B12-modified amphiphilic chitosan derivatives to treat type II diabetes induced-retinopathy. J Nanobiotechnol 15(1):18. https://doi.org/10.1186/s1295 1-017-0251-z

79. Ortiz-Andrade RR, Sanchez-Salgado JC, Navarrete-Vazquez G, Webster SP, Binnie M, Garcia-Jimenez S, Leon-Rivera I, Cigarroa-Vazquez P, Villalobos-Molina R, Estrada-Soto $S$ (2008) Antidiabetic and toxicological evaluations of naringenin in normoglycaemic and NIDDM rat models and its implications on extra-pancreatic glucose regulation. Diabetes Obes Metab 10(11):1097-1104. https://doi.org/10.111 1/j.1463-1326.2008.00869.x

80. Ahangarpour A, Oroojan AA, Khorsandi L, Kouchak M, Badavi M (2018) Solid lipid nanoparticles of myricitrin have antioxidant and antidiabetic effects on streptozotocin-nicotinamide-induced diabetic model and myotube cell of male mouse. Oxid Med Cell Longev 2018:7496936. https://doi. org/10.1155/2018/7496936

81. Kaliamurthi S, Selvaraj G, Thirugnanasamb R, Thangavel B (2018) Topical delivery of nano-encapsulated rutoside medication for diabetic foot ulcer in rat model. Nanosci Nanotechnol Asia 8(1):116-129

82. Singh J, Mittal P, Vasant Bonde G, Ajmal G, Mishra B (2018) Design, optimization, characterization and in vivo evaluation of quercetin enveloped soluplus ${ }^{(\mathrm{R})} / \mathrm{P} 407$ micelles in diabetes treatment. Artif Cells Nanomed Biotechnol 46:S546-s555

83. Chitkara D, Nikalaje SK, Mittal A, Chand M, Kumar N (2012) Development of quercetin nanoformulation and in vivo evaluation using streptozotocin induced diabetic rat model. Drug Deliv Transl Res 2(2):112-123. https://doi.org/10.1007/s1334 6-012-0063-5

84. Mukhopadhyay P, Maity S, Mandal S, Chakraborti AS, Prajapati AK, Kundu PP (2018) Preparation, characterization and in vivo evaluation of $\mathrm{pH}$ sensitive, safe quercetin-succinylated chitosan-alginate core-shell-corona nanoparticle for diabetes treatment. Carbohydr Polym 182:42-51. https://doi. org/10.1016/j.carbpol.2017.10.098

85. Malakouti M, Kataria A, Ali SK, Schenker S (2017) Elevated liver enzymes in asymptomatic patients: what should I do? J Clin Transl Hepatol 5(4):394-403. https://doi.org/10.14218/ JCTH.2017.00027

86. Butterfield DAJA (2006) Oxidative stress in neurodegenerative disorders. Antioxid Redox Signal 8(11-12):1971-1973

87. Costa LG, Garrick JM, Roque PJ, Pellacani C (2016) Mechanisms of neuroprotection by quercetin: counteracting oxidative stress and more. Oxid Med Cell Longev 2016:2986796. https://doi. org/10.1155/2016/2986796

88. Lu J, Wu DM, Zheng YL, Hu B, Zhang ZF, Shan Q, Zheng ZH, Liu CM, Wang YJ (2010) Quercetin activates AMP-activated protein kinase by reducing PP2C expression protecting old mouse brain against high cholesterol-induced neurotoxicity. J Pathol 222(2):199-212. https://doi.org/10.1002/path.2754

89. Pugazhenthi S, Qin L (1863) Reddy PH (2017) Common neurodegenerative pathways in obesity, diabetes, and Alzheimer's disease. Biochim Biophys Acta Mol Basis Dis 5:1037-1045. https ://doi.org/10.1016/j.bbadis.2016.04.017

90. Miao Y, He T, Zhu Y, Li W, Wang B, Zhong Y (2015) Activation of hippocampal CREB by rolipram partially recovers balance between TNF-alpha and IL-10 levels and improves cognitive deficits in diabetic rats. Cell Mol Neurobiol 35(8):1157-1164. https://doi.org/10.1007/s10571-015-0209-3

91. Ademosun AO, Oboh G, Bello F, Ayeni PO (2016) Antioxidative properties and effect of quercetin and its glycosylated form (rutin) on acetylcholinesterase and butyrylcholinesterase activities. J Evid Based Complement Altern Med 21(4):11-17. https ://doi.org/10.1177/2156587215610032

92. Gu HF, Ma J, Gu KT, Brismar K (2012) Association of intercellular adhesion molecule 1 (ICAM1) with diabetes and diabetic nephropathy. Front Endocrinol (Lausanne) 3:179. https://doi. org/10.3389/fendo.2012.00179

93. Wu K, Liang T, Duan X, Xu L, Zhang K, Li R (2013) Anti-diabetic effects of puerarin, isolated from Pueraria lobata (Willd.), on streptozotocin-diabetogenic mice through promoting insulin expression and ameliorating metabolic function. Food Chem Toxicol 60:341-347. https://doi.org/10.1016/j.fct.2013.07.077 
94. Wang T, Wang N, Song H, Xi X, Wang J, Hao A, Li T (2011) Preparation of an anhydrous reverse micelle delivery system to enhance oral bioavailability and anti-diabetic efficacy of berberine. Eur J Pharm Sci 44(1-2):127-135. https://doi. org/10.1016/j.ejps.2011.06.015

95. Das S, Roy P, Pal R, Auddy RG, Chakraborti AS, Mukherjee A (2014) Engineered silybin nanoparticles educe efficient control in experimental diabetes. PLoS ONE 9(7):e101818. https://doi. org/10.1371/journal.pone.0101818

96. Al-Bishri WM (2017) Attenuating impacts of chromium and nano resveratrol against hyperglycemia induced oxidative stress in diabetic rats. Int J Pharm Res Allied Sci 6(2):61-69

97. El-Far YM, Zakaria MM, Gabr MM, El Gayar AM, Eissa LA, EISherbiny IM (2017) Nanoformulated natural therapeutics for management of streptozotocin-induced diabetes: potential use of curcumin nanoformulation. Nanomedicine (Lond) 12(14):1689-1711. https://doi.org/10.2217/nnm-2017-0106

98. Gouda W, Hafiz N, Mageed L, Alazzouni A, Khalil W, Afify M, Abdelmaksoud M (2019) Effects of nano-curcumin on gene expression of insulin and insulin receptor. Bull Natl Res Cent. https://doi.org/10.1186/s42269-019-0164-0

99. Jia TY, Rao JA, Zou LF, Zhao SH, Yi ZH, Wu B, Li L, Yuan HL, Shi LR, Zhang CP, Gao Y, Liu SM, Xu H, Liu H, Liang SD, Li GL (2018) Nanoparticle-encapsulated curcumin inhibits diabetic neuropathic pain involving the $\mathrm{P} 2 \mathrm{Y} 12$ receptor in the dorsal rootganglia. Front Neurosci-Switz 11

100. Joshi RP, Negi G, Kumar A, Pawar YB, Munjal B, Bansal AK, Sharma SS (2013) SNEDDS curcumin formulation leads to enhanced protection from pain and functional deficits associated with diabetic neuropathy: an insight into its mechanism for neuroprotection. Nanomedicine 9(6):776-785

101. Abdel-Mageid AD, Abou-Salem MES, Salaam NMHA, El-Garhy HAS (2018) The potential effect of garlic extract and curcumin nanoparticles against complication accompanied with experimentally induced diabetes in rats. Phytomedicine 43:126-134. https://doi.org/10.1016/j.phymed.2018.04.039

102. Tong $F$, Chai $R$, Jiang $H$, Dong $B(2018)$ In vitro/vivo drug release and anti-diabetic cardiomyopathy properties of curcumin/ PBLG-PEG-PBLG nanoparticles. Int J Nanomed 13:1945-1962. https://doi.org/10.2147/ijn.S153763

103. El-Naggar ME, Al-Joufi F, Anwar M, Attia MF, El-Bana MA (2019) Curcumin-loaded PLA-PEG copolymer nanoparticles for treatment of liver inflammation in streptozotocin-induced diabetic rats. Colloids Surf B Biointerfaces 177:389-398

104. Ganugula R, Arora M, Jaisamut $P$, Wiwattanapatapee $R$, Jorgensen HG, Venkatpurwar VP, Zhou B, Rodrigues Hoffmann A, Basu R, Guo S, Majeti N (2017) Nano-curcumin safely prevents streptozotocin-induced inflammation and apoptosis in pancreatic beta cells for effective management of Type 1 diabetes mellitus. Br J Pharmacol 174(13):2074-2084

105. Devadasu VR, Wadsworth RM, Kumar MN (2011) Protective effects of nanoparticulate coenzyme Q10 and curcumin on inflammatory markers and lipid metabolism in streptozotocin-induced diabetic rats: a possible remedy to diabetic complications. Drug Deliv Transl Res 1(6):448-455. https://doi. org/10.1007/s13346-011-0041-3

106. Grama CN, Suryanarayana P, Patil MA, Raghu G, Balakrishna N, Kumar MN, Reddy GB (2013) Efficacy of biodegradable curcumin nanoparticles in delaying cataract in diabetic rat model. PLoS ONE 8(10):e78217. https://doi.org/10.1371/journ al.pone.0078217

107. Rouse $M$, Younès $A$, Egan JM (2014) Resveratrol and curcumin enhance pancreatic $\beta$-cell function by inhibiting phosphodiesterase activity. J Endocrinol 223(2):107-117. https://doi. org/10.1530/JOE-14-0335
108. Ohara PT, Vit JP, Bhargava A, Jasmin L (2008) Evidence for a role of connexin 43 in trigeminal pain using RNA interference in vivo. J Neurophysiol 100(6):3064-3073. https://doi. org/10.1152/jn.90722.2008

109. Ren K, Torres R (2009) Role of interleukin-1beta during pain and inflammation. Brain Res Rev 60(1):57-64. https://doi. org/10.1016/j.brainresrev.2008.12.020

110. Sun R, Yan J, Willis WD (2007) Activation of protein kinase B/ Akt in the periphery contributes to pain behavior induced by capsaicin in rats. Neuroscience 144(1):286-294. https://doi. org/10.1016/j.neuroscience.2006.08.084

111. Horváth G, Gölöncsér F, Csölle $C$, Kiraly K, Andó R, Baranyi $M$, Kovanyi B, Máté Z, Hoffmann K, Algaier I, Baqi Y, Mueller C, von Kügelgen I, Sperlágh B (2014) Central P2Y12 receptor blockade alleviates inflammatory and neuropathic pain and cytokine production in rodents. Neurobiol Dis. https://doi.org/10.1016/j. nbd.2014.06.011

112. Ye $P, G u Y$, Zhu $Y R$, Chao $Y L$, Kong $X Q$, Luo J, Ren $X M$, Zuo GF, Zhang DM, Chen SL (2018) Exogenous hydrogen sulfide attenuates the development of diabetic cardiomyopathy via the FoxO1 pathway. J Cell Physiol 233(12):9786-9798. https:// doi.org/10.1002/jcp.26946

113. Martin H (2010) Role of PPAR-gamma in inflammation. Prospects for therapeutic intervention by food components. Mutat Res 690(1-2):57-63. https://doi.org/10.1016/j.mrfmm m.2009.09.009

114. Li L, Sheng X, Zhao SH, Zou LF, Han XY, Gong YX, Yuan HL, Shi LR, Guo LL, Jia TY, Liu SM, Wu B, Yi ZH, Liu H, Gao Y, Li GL, Li GD, Zhang CP, Xu H, Liang SD (2017) Nanoparticle-encapsulated emodin decreases diabetic neuropathic pain probably via a mechanism involving $\mathrm{P} 2 \mathrm{X} 3$ receptor in the dorsal root ganglia. Purinergic Signal 13(4):559-568

115. Stephan G, Huang L, Tang Y, Vilotti S, Fabbretti E, Yu Y, Nörenberg W, Franke H, Gölöncsér F, Sperlágh B (2018) The ASIC3/ $\mathrm{P} 2 \mathrm{X} 3$ cognate receptor is a pain-relevant and ligand-gated cationic channel. Nat Commun 9(1):1354

116. Leung L, Cahill CM (2010) TNF-alpha and neuropathic pain: a review. J Neuroinflamm 7:27. https://doi. org/10.1186/1742-2094-7-27

117. Ji R-R, Gereau RW, Malcangio M, Strichartz GR (2009) MAP kinase and pain. Brain Res Rev 60(1):135-148. https://doi. org/10.1016/j.brainresrev.2008.12.011

118. Costes S, Broca C, Bertrand G, Lajoix A-D, Bataille D, Bockaert J, Dalle SJD (2006) ERK1/2 control phosphorylation and protein level of CAMP-responsive element-binding protein: a key role in glucose-mediated pancreatic $\beta$-cell survival. Diabetes 55(8):2220-2230

119. Bitencourt PE, Cargnelutti LO, Stein CS, Lautenchleger $R$, Ferreira LM, Sangoi M, Denardi L, Borges RM, Boligon A, Moresco RN, Cruz L, Zanette RA, Alves SH, Moretto MB (2017) Nanoparticle formulation increases Syzygium cumini antioxidant activity in Candida albicans-infected diabetic rats. Pharm Biol 55(1):1082-1088. https://doi.org/10.1080/13880 209.2017.1283338

120. Zupancic S, Lavric Z, Kristl J (2015) Stability and solubility of trans-resveratrol are strongly influenced by $\mathrm{pH}$ and temperature. Eur J Pharm Biopharm 93:196-204. https://doi. org/10.1016/j.ejpb.2015.04.002

121. Pakade V, Lesaoana $M$, Tavengwa $N$ (2016) The effect of $\mathrm{pH}$, time and temperature on forced degradation studies of quercetin in presence of polymers. Asian J Chem 28:2181-2187. https:// doi.org/10.14233/ajchem.2016.19913

122. Davatgaran-Taghipour $Y$, Masoomzadeh S, Farzaei MH, Bahramsoltani R, Karimi-Soureh Z, Rahimi R, Abdollahi M (2017) Polyphenol nanoformulations for cancer therapy: experimental 
evidence and clinical perspective. Int J Nanomed 12:26892702. https://doi.org/10.2147/ijn.S131973

123. Liechty WB, Kryscio DR, Slaughter BV, Peppas NA (2010) Polymers for drug delivery systems. Annu Rev Chem Biomol Eng 1:149-173. https://doi.org/10.1146/annurev-chembioeng $-073009-100847$

124. Schmaljohann $\mathrm{D}$ (2006) Thermo- and $\mathrm{pH}$-responsive polymers in drug delivery. Adv Drug Deliv Rev 58(15):1655-1670. https ://doi.org/10.1016/j.addr.2006.09.020

125. Hoffman A (2013) Applications of "smart polymers" as biomaterials. In: Ratner BD, Hoffman AS, Schoen FJ, Lemons JE (eds) Biomaterials science: an introduction to materials in medicine, 3rd edn. Academic Press, Cambridge, pp 247-258. https://doi. org/10.1016/b978-0-08-087780-8.00026-7

126. Mahajan A, Aggarwal G (2011) Smart polymers: innovations in novel drug delivery. Int J Drug Dev Res 3:16-30

127. Hua S, de Matos MBC, Metselaar JM, Storm G (2018) Current trends and challenges in the clinical translation of nanoparticulate nanomedicines: pathways for translational development and commercialization. Front Pharmacol 9:790. https:// doi.org/10.3389/fphar.2018.00790
128. Wu L-P, Wang D, Li Z (2020) Grand challenges in nanomedicine. Mater Sci Eng C 106:110302. https://doi.org/10.1016/j. msec.2019.110302

129. Langer K, Anhorn MG, Steinhauser I, Dreis S, Celebi D, Schrickel $\mathrm{N}$, Faust S, Vogel V (2008) Human serum albumin (HSA) nanoparticles: reproducibility of preparation process and kinetics of enzymatic degradation. Int J Pharm 347(1-2):109-117. https:// doi.org/10.1016/j.ijpharm.2007.06.028

130. Sufian MM, Khattak JZK, Yousaf S, Rana MS (2017) Safety issues associated with the use of nanoparticles in human body. Photodiagnosis Photodyn Ther 19:67-72. https://doi.org/10.1016/j. pdpdt.2017.05.012

131. Suffredini G, East JE, Levy LM (2014) New applications of nanotechnology for neuroimaging. AJNR Am J Neuroradiol 35(7):1246-1253. https://doi.org/10.3174/ajnr.A3543

Publisher's Note Springer Nature remains neutral with regard to jurisdictional claims in published maps and institutional affiliations. 